\title{
Increasing Temperature, Not Mean Temperature, Is a Cue for Avian Timing of Reproduction
}

\author{
Sonja V. Schaper, ${ }^{1, *}$ Alistair Dawson, ${ }^{2}$ Peter J. Sharp, ${ }^{3}$ Phillip Gienapp, ${ }^{4}$ Samuel P. Caro, ${ }^{1}$ and \\ Marcel E. Visser ${ }^{1}$ \\ 1. Department of Animal Ecology, Netherlands Institute of Ecology (NIOO-KNAW), P.O. Box 50, 6700 AB Wageningen, The \\ Netherlands; 2. Centre for Ecology and Hydrology, Bush Estate, Penicuik, Midlothian EH26 0QB, United Kingdom; 3. Roslin Institute \\ and Royal (Dick) School of Veterinary Studies, University of Edinburgh, Edinburgh, Midlothian EH25 9RG, United Kingdom; \\ 4. Ecological Genetics Research Unit, Department of Biosciences, University of Helsinki, Viikinkaari 11, FIN-00014 Helsinki, Finland
}

Submitted March 1, 2011; Accepted September 22, 2011; Electronically published December 20, 2011

Online enhancements: appendixes. Dryad data: http://dx.doi.org/10.5061/dryad.22pm2619.

ABSTRACT: Timing of reproduction in temperate-zone birds is strongly correlated with spring temperature, with an earlier onset of breeding in warmer years. Females adjust their timing of egg laying between years to be synchronized with local food sources and thereby optimize reproductive output. However, climate change currently disrupts the link between predictive environmental cues and spring phenology. To investigate direct effects of temperature on the decision to lay and its genetic basis, we used pairs of great tits (Parus major) with known ancestry and exposed them to simulated spring scenarios in climate-controlled aviaries. In each of three years, we exposed birds to different patterns of changing temperature. We varied the timing of a temperature change, the daily temperature amplitude, and the onset and speed of a seasonal temperature rise. We show that females fine-tune their laying in response to a seasonal increase in temperature, whereas mean temperature and daily temperature variation alone do not affect laying dates. Luteinizing hormone concentrations and gonadal growth in early spring were not influenced by temperature or temperature rise, possibly posing a constraint to an advancement of breeding. Similarities between sisters in their laying dates indicate genetic variation in cue sensitivity. These results refine our understanding of how changes in spring climate might affect the mismatch in avian timing and thereby population viability.

Keywords: timing of reproduction, supplementary cues, temperature, laying date, Parus major, avian breeding season.

\section{Introduction}

The timing of life-cycle events, such as breeding and migration in birds, is a phenomenon that has intrigued biologists for decades. In the temperate zone, strong seasonal fluctuations in food availability determine a short period in spring suitable for reproduction in terms of energy and

\footnotetext{
* Corresponding author; e-mail: s.schaper@nioo.knaw.nl.
}

Am. Nat. 2012. Vol. 179, pp. E55-E69. (c) 2011 by The University of Chicago. 0003-0147/2012/17902-52857\$15.00. All rights reserved. DOI: $10.1086 / 663675$ nutrient availability (Lack 1968; Perrins 1970; Verhulst and Tinbergen 1991). In this period, birds have to lay eggs and raise their offspring. After breeding, they require energy for molt, which has to be completed before conditions deteriorate. The timing of these connected life-cycle stages is crucial to maximize individual fitness (Wingfield and Kenagy 1991; Grieco et al. 2002; Both et al. 2004; Visser and Both 2005; Visser et al. 2006; Wingfield 2008). If the period of chick feeding matches the appropriate local food peak, both fledgling survival (Perrins 1965; van Noordwijk et al. 1995; Sheldon et al. 2003; Charmantier et al. 2008) and parental condition and survival (Thomas et al. 2001) are enhanced.

Because the timing of the food peak differs among years, temperate-zone birds, such as great tits (Parus major), show large annual variation in the onset of laying. This variation is largely due to phenotypic plasticity (Pigliucci 2001): females vary their laying dates according to climatic conditions. Great tits lay earlier, on average, in warm springs (e.g., Kluyver 1952; Perrins 1965; van Balen 1973; Schmidt 1984; Perrins and McCleery 1989), but individuals also differ consistently in their laying date relative to the yearly population mean (Nussey et al. 2005). This can be explained by two possibly complementary hypotheses: first, females differ in their costs of egg production, allowing only high-quality birds to breed at the optimal time, and second, females differ in their use of environmental cues to assess the optimal laying date (Visser et al. 1998, $2010 b)$.

Among these cues, increasing day length is considered an initial predictive cue (Silverin et al. 1993; Wingfield 1993; Dawson et al. 2001), acting either directly or via the entrainment of an endogenous circannual rhythm (Gwinner 1986, 1996). Exposure to long days stimulates luteinizing and follicle-stimulating hormone secretion, gonadal 
development, and sex steroid synthesis and release, which facilitates the start of breeding. However, supplementary cues (Wingfield and Kenagy 1991; Wingfield et al. 1992; Dawson 2008), such as temperature, provide information about local conditions and accelerate or delay reproductive development. Observations of tropical birds show a direct relationship between supplementary cues and the onset of breeding (Hau et al. 2000; Wikelski et al. 2000; Hau 2001), but this has seldom been experimentally investigated in temperate-zone birds.

Many tree species, and also arboreal caterpillars that passerine birds rely on in spring to feed their chicks (Perrins 1991; Naef-Daenzer et al. 2000; Visser et al. 2006), respond directly to temperature (van Asch et al. 2007). Field observations show a negative relationship between spring temperatures and mean laying date (Slagsvold 1976; Perrins and McCleery 1989; Crick et al. 1997; McCleery and Perrins 1998; Sokolov 2000; Both et al. 2004; but cf. exceptions in Visser et al. 1998, 2003); however, they never exclude the possibility of indirect temperature effects via, for instance, spring phenology. Experiments comparing artificially heated or cooled nest boxes (Nager and van Noordwijk 1992; Yom-Tov and Wright 1993) failed to provide unambiguous evidence for an advancement in laying through warming. Most laboratory-based experiments employ a strong increase in photoperiod or compare constant and extreme temperatures (Storey and Nicholls 1982; Silverin and Viebke 1994; Silverin 1995; Wingfield et al. 1996, 1997, 2003), although not all do so (Suomalainen 1937; Perfito et al. 2005). Moreover, laying under controlled conditions is rare because of the difficulties of providing captive birds with an environment where they reproduce (but see Meijer et al. 1999; Lambrechts and Perret 2000; Caro et al. 2007). Visser et al. (2009) simulated temperature patterns recorded during years in which mean laying dates in the wild population of great tits differed by 2 weeks. They showed that females under simulated cold/late-year conditions delayed their reproduction compared to the group under warm/early-year conditions. In contrast, Visser et al. (2011), using linear temperature increases differing only in mean temperature, found no distinction in laying dates. Apparently, a constant difference did not capture the temperature effect from the mimicked cold and warm years used by Visser et al. (2009).

Our aim was to unravel the characteristics of a seasonal temperature profile that affect laying dates of great tits. We used unique climate-controlled bird facilities to observe egg laying under controlled photoperiod and temperature conditions. Furthermore, we analyzed temperature effects on endocrine and gonadal development and postnuptial molt, encompassing a large part of the avian life cycle under simulated environmental conditions.

In 2008, we lowered ambient temperature at specific time periods while keeping a control group at a constant temperature. If mean temperature acts as a cue, then birds under constant warm conditions should lay first. Furthermore, if temperature cues become more important as the season proceeds, we expect birds under cold conditions late in spring to lay latest. In 2009, we investigated whether daily variation in temperature affects the onset of laying. Under natural conditions, the difference between daily maximum and minimum temperatures increases progressively during spring. We therefore evaluated the effect of a high or low 24-h temperature amplitude embedded within a high or low mean temperature. If birds respond to daily temperature changes, then females that experience high fluctuations around a warm mean should lay first. Furthermore, if minimum temperature, which restricts the development of invertebrate food (Partridge et al. 1994; Petavy et al. 2001), serves as a cue, then we expect birds experiencing the lowest temperatures to lay latest. In 2010, we simulated patterns of spring increases in temperature that differed in their timing, speed, and maximum, as well as in the timing of a subsequent temperature rise just before laying. If birds use the increase in early spring as a cue, then birds exposed to an early and steep temperature increase should lay first. However, if birds fine-tune their laying by using the temperature rise immediately preceding laying, then we expect a (potentially additional) advancement.

When individuals vary their timing in response to a cue and this response has a genetic component (van der Jeugd and McCleery 2002; Sheldon et al. 2003; McCleery et al. 2004; Nussey et al. 2005), it is crucial to compare related individuals in controlled experiments. Here we present the outcome of three years of experiments on birds of known ancestry from a long-term monitored population.

\section{Material and Methods}

\section{Birds}

We used 36 first-year breeding pairs of great tits in each of the three years. Birds were collected from a long-term study population at the Hoge Veluwe National Park (Netherlands) and taken to captivity as nestlings in 2007-2009. Each year, 10 broods were selected from specifically earlyor late-laying maternal lines: five early and five late broods (avoiding replacement broods) with known information about the previous early- or late-laying history of the female herself and/or her mother and grandmother. All chicks were blood sampled when 3 days old and sexed (Griffiths et al. 1998), and extrapair offspring were identified (Saladin et al. 2003) before brood choice. On day 10 after hatching, chicks were taken for hand-raising (Drent et al. 2003) to the Netherlands Institute of Ecology 
(Heteren), where they were weighed (chick weights) as a proxy for early environment condition.

We tested all fledglings for exploration behavior in a novel environment as a measure of personality (Verbeek et al. 1994; Dingemanse et al. 2002). Afterward, they were transferred to open outdoor aviaries $(2 \mathrm{~m} \times 4 \mathrm{~m} \times 2.5$ $\mathrm{m})$, where they were housed in groups. In December, breeding pairs were formed randomly, avoiding sib matings. In 2008 and 2010, early-laid females were paired with early-laid males and vice versa, while in 2009 all four possible combinations of pairs were formed to decouple sexspecific effects. On December 1, the birds were placed in climate-controlled aviaries to breed in the next year.

Because of fatalities in the young birds from the Hoge Veluwe, we formed some pairs by using additional handraised birds with known laying dates. In 2008, five females and three males from an adjacent field site were used. In 2009 and 2010, birds hatched from eggs laid by captive great tits but cross-fostered and raised by wild parents until day 10 , the start of hand-rearing, were used: eight females and four males in 2009, one female and nine males in 2010.

\section{Aviaries}

We kept the breeding pairs in 36 separate indoor aviaries $(2 \mathrm{~m} \times 2 \mathrm{~m} \times 2.25 \mathrm{~m})$ under a photoperiod that was adapted twice a week following the natural change in day length (for $52^{\circ} \mathrm{N}$, increasing from $7: 45 \mathrm{~L}: 16: 15 \mathrm{D}$ at the winter solstice to $16: 30 \mathrm{~L}: 7: 30 \mathrm{D}$ at the summer solstice). Light sources were three high-frequency fluorescent light tubes, complemented with an 8-W bulb for an additional half-hour of dawn and dusk. A roof shaft (SolaTube), synchronized with the light schedule, opened to allow for supplementary daylight.

The birds were fed ad lib. with a constant daily amount of food (Visser et al. 2011). Nesting material was provided from March onward. Birds could choose between two nest boxes, which we inspected for eggs from outside the aviary without disturbance.

\section{Temperature Treatments}

Previous studies (Visser et al. 2009, 2011) showed that birds vary their egg-laying behavior with temperature in the absence of other supplementary cues. The study described here extends previous results to pinpoint which aspects of a temperature profile influence laying dates. The temperatures are well within the ranges present in our study area over the past 10 years (maxima of $15^{\circ} / 14^{\circ} \mathrm{C}$ in December/January and minima of $6.5^{\circ} / 6^{\circ} \mathrm{C}$ in July/August, respectively). Each season, a different setup of four tem- perature treatments was used (fig. 1, left), replicated in a regular design over nine aviaries.

Our aim in 2008 was to examine at which springtime period females were most sensitive to temperature changes. All four treatment groups were kept at a constant temperature of $15^{\circ} \mathrm{C}$ from December onward. In three groups, this temperature was lowered to $7^{\circ} \mathrm{C}$ for a month, in February, March, or April, before it was increased to $15^{\circ} \mathrm{C}$ again, except for the latest cold period, which was maintained until the female initiated laying under cold conditions (fig. 1A). When a female started molting, that is, shed the first primary feather, temperature was increased to $20^{\circ} \mathrm{C}$ in each aviary individually.

In 2009, our experiment focused on effects of daily fluctuation in temperature. If temperatures were not perceived as absolute values but rather as daily variation, this would allow a bird to measure the progress of spring via the experienced temperature amplitude over a day. To investigate this, we exposed birds to one of four temperature treatments, each composed of a high or low mean temperature with either a high or low day-night amplitude (fig. 1D). The warm treatments fluctuated around $14^{\circ} \mathrm{C}$ $\left(11^{\circ}-17^{\circ} \mathrm{C}\right.$ for high amplitude, $13^{\circ}-15^{\circ} \mathrm{C}$ for low amplitude) and the cold treatments around $8^{\circ} \mathrm{C}\left(5^{\circ}-11^{\circ} \mathrm{C}\right.$ for high amplitude, $7^{\circ}-9^{\circ} \mathrm{C}$ for low amplitude). The minimum was reached at 3:00 a.m. There was no seasonal pattern. When females started molting, the temperature was increased to $20^{\circ} \mathrm{C}$.

The 2010 setup combined two consecutive temperature rises, one during early gonadal development and the other shortly before breeding. We initially kept all birds at $6^{\circ} \mathrm{C}$. On February 8 (January day 39 ), the temperature was increased rapidly for two groups from $6^{\circ}$ to $16^{\circ} \mathrm{C}$ over the course of 2 weeks and then maintained at $16^{\circ} \mathrm{C}$ for 3 or 5 weeks (fig. $1 G$ ). Starting on March 15 or 29, the temperature was increased to $20^{\circ} \mathrm{C}$ over 1 week and stayed high during egg laying and molt. Starting on February 22 (January day 53), the other two groups were exposed to a more gradual increase in temperature, from $6^{\circ}$ to $11^{\circ} \mathrm{C}$ over a course of 2 weeks, thus experiencing a lower increase rate. These groups were then held at $11^{\circ} \mathrm{C}$ for 1 or 3 weeks. Starting on March 15 or 29, temperature was increased to $15^{\circ} \mathrm{C}$ for egg laying and molt (fig. $1 G$ ). Superimposed on the temperature profiles was a day-night rhythm of $\pm 1^{\circ} \mathrm{C}$.

\section{Data Collection}

We checked nest boxes daily for eggs, which were collected and replaced by eggs taken from nests of wild great tits used in cross-fostering experiments. Complete nests were removed after 5 days of incubation, after which some females rebuilt nests and initiated new clutches. The day the first egg was found is referred to as the laying date, and 
Temperature treatments
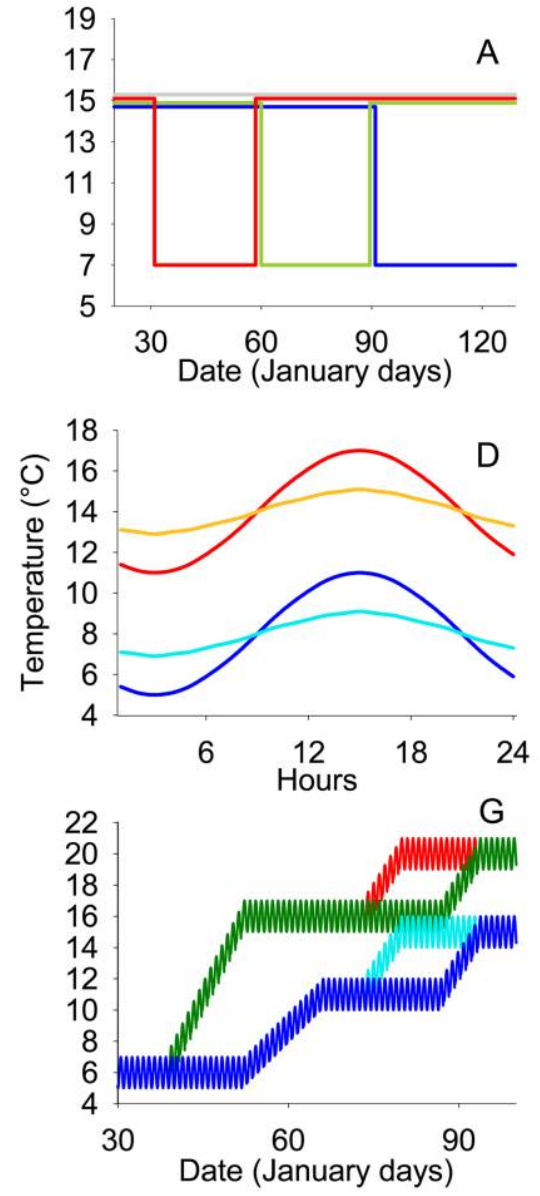

Early females

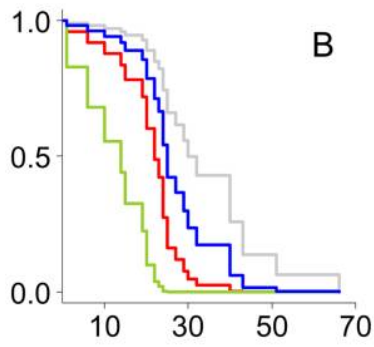

B

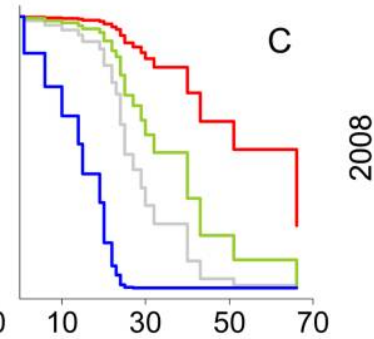

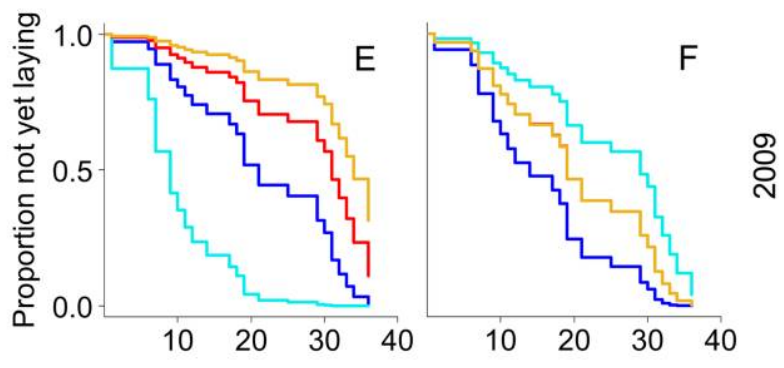
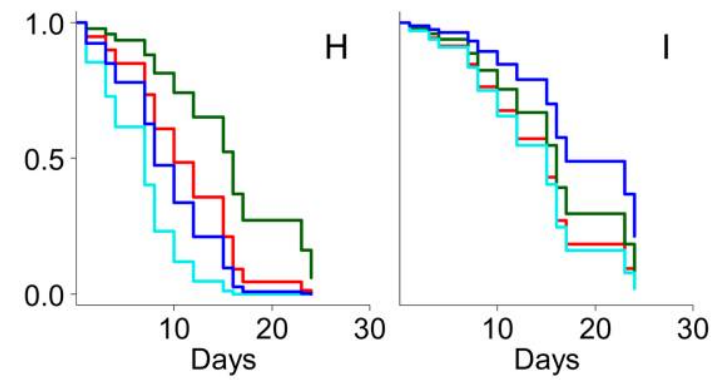

Figure 1: Temperature treatments (left) and their effect on the onset of laying for females from early (middle) and late families (right) in climate-controlled aviaries in $2008(A-C), 2009(D-F)$, and $2010(G-I)$. Colors of the temperature patterns on the left identify the treatments in all subsequent graphs. For a description of the treatments see "Material and Methods." Note that in 2009 the temperature pattern did not vary seasonally. $B, C, E, F, H, I$, Survival graphs showing the outcome of the proportional hazard model in table $1 a$. Lines show the proportion of females per treatment that are not yet laying in relation to the first laying date of the year. The middle panels show the earliest-laying family of each year (mother's laying dates: April 7, 2008; April 3, 2009; April 8, 2010) and the right-hand panels the latestlaying family (mother's laying dates: April 20, 2008; April 26, 2009; April 18, 2010). Days represent days after the first laying date: April 17, 2008, April 15, 2009, and April 23, 2010. A fast-descending line represents a group that starts laying early. Note that in $F$ the red and yellow lines are superimposed.

the day the last egg of the last clutch was laid is referred to as the date of termination of reproduction.

A $100-\mu$ L blood sample was taken monthly from the jugular vein. Samples were kept on ice until centrifugation, and plasma was separated and stored at $-80^{\circ} \mathrm{C}$. Plasma luteinizing hormone (LH) concentrations were determined with a chicken LH radioimmunoassay (Sharp et al. 1987) validated for use in blue tits (Caro et al. 2006). The assay reaction volume was $60 \mu \mathrm{L}$, comprising $20 \mu \mathrm{L}$ of plasma sample or standard, $20 \mu \mathrm{L}$ of primary antibody (rabbit anti-LH), and $20 \mu \mathrm{L}$ of ${ }^{125} \mathrm{I}$-labeled $\mathrm{LH}$. The pri- mary antibody was precipitated to separate free and bound ${ }^{125} \mathrm{I}$ label by use of $20 \mu \mathrm{L}$ of donkey antirabbit precipitating serum and $20 \mu \mathrm{L}$ of nonimmune rabbit serum. All samples from each year were measured in a single assay, in duplicate. The intra-assay coefficient of variation was $6.4 \%$ for a high-value pool and $8.1 \%$ for a low-value pool; the minimum detectable dose was $0.15 \mathrm{ng} / \mathrm{mL}$.

In alternation with blood sampling, we performed a monthly laparotomy to measure gonadal development. Males were assessed from January to July and females up to April in order not to interfere with laying. However, in 
2009 females were not laparotomized in April, with no effect on the onset of laying, and in 2010 we did no laparotomy in January, as little variation in gonad sizes had been shown in previous years. Birds were unilaterally laparotomized under isoflurane anesthesia (Forene, Abbott, Hoofddorp, Netherlands). Left-testis length and width and the diameter of the largest follicle in the ovary were measured to the nearest $0.1 \mathrm{~mm}$ with an ocular scale. Testis volume was calculated as $V=4 / 3 \pi a^{2} b$, where $a$ is half the width and $b$ is half the length; follicle volume was calculated as $V=4 / 3 \pi a^{3}$, where $a$ is half the width.

We recorded the molt of the primary wing feathers biweekly in 2008 and weekly in 2009 and 2010. The molt score was calculated following Dawson and Newton (2004), with great tit-specific parameters from Dawson $(2005 b)$. For each individual, date was linearly regressed against molt score. The onset (intercept) and speed (slope) of molt allowed us to calculate molt duration.

\section{Statistical Analyses}

The onset or termination of reproduction can be viewed as a "time to event" and analyzed with mixed-effects Cox proportional hazard models (Cox 1972). The probability that an animal will start laying on a particular day is a function of an unspecified baseline hazard (Kalbfleisch and Prentice 2002) multiplied by a number of explanatory variables, which include fixed as well as time-dependent variables. This approach has been applied to the analysis of timing of reproduction and migration of wild populations (Gienapp et al. 2005, 2010; Bauer et al. 2008).

The advantage of this method over regression of individual observations against a temperature measure is that there is no need to specify a fixed time period of interest. Instead, we used an iterative procedure based on a linear predictor for the calculation of a temperature variable $(\lambda)$ that incorporates the current as well as earlier temperatures experienced by the organisms (for details, see Gienapp et al. 2005). A weighting factor $(\alpha)$ assesses the relative importance of current versus earlier temperatures: if this factor is large, the model places a high weight on the most recent temperature (the temperature variable resembles the mean of that particular day), while if it is small, previous temperatures are given more importance, which implies a longer "memory" of temperature conditions. Values for the weighting factor ranged from 0.01 to 0.2 in increments of 0.01 . In the model-reduction process (based on a partial maximum likelihood method), the best linear temperature predictor $\lambda$ was recalculated in each reduction step. The mean December temperature of individual aviaries was used as a starting value, and daily mean temperatures modified by the weighting factor were used as time-dependent variables. Use of minimum temperatures did not give qualitatively different results. Statistical significance was tested with likelihood ratio tests (Therneau and Grambsch 2000). We used the coxme (including random effects) and coxph procedures from package kinship in R 2.10.0 ( $\mathrm{R}$ Development Core Team 2009).

Temperature was coded either as a four-level treatment or as time-dependent realized temperatures (integrated by $\alpha$ and therefore including within-treatment variation over time). For each year, a complex model incorporated female family as a random factor, temperature, chick weight (measure for early-life condition), personality (responsiveness to environmental variability and social stimuli), and date of birth (date of the mother's first egg of the clutch from which that bird originated, i.e., early- and late-laid birds). Furthermore, the interaction between female date of birth and temperature was added. The time-dependent interaction between photoperiod and temperature was included in the model for onset of laying. Because day length is linearly related to date, it was impossible to include as a main effect. In 2009, the genetic composition of the pair (e.g., early-laid female-late-laid male) was added. In addition, models that used only female or male family as explanatory variables while controlling for temperature treatment were used to assess differences in laying behavior between families.

Gonadal development was analyzed in mixed models (procedure lmer, package lme4 in R 2.10.0), with individual as a random effect. Data on gonadal maturation (January-April) was log transformed to account for exponential growth. Fixed effects were month, tarsus length as a measure of body size, temperature treatment, date of birth, and the interaction between temperature treatment and date of birth. Male gonadal regression did not follow a negative exponential pattern, and log transformation did not facilitate a better model fit. Testis volume was therefore analyzed separately for May-July. As tarsus length was not correlated to gonadal growth, it was excluded from the analyses of gonadal regression. Family was fitted as a random effect.

Luteinizing hormone levels were log transformed and analyzed over the whole season in mixed models using individual and family as nested random effects. Fixed effects were month as a factor, temperature treatment, date of birth, personality, and date of birth of the mate as well as the interactions between temperature treatment and month and temperature treatment and date of birth.

Onset and duration of molt were analyzed in mixed models using family as a random effect. First, laying/nonlaying birds were compared, showing that birds that skip reproduction mostly start molt earlier. A subsequent analysis included only laying pairs and used date of termination of reproduction, temperature treatment, and date of birth as fixed effects. 


\section{Results}

\section{Onset of Reproduction}

In 2008, when the effect of cold periods in different spring months was tested, 24 out of 36 pairs initiated at least one clutch, starting on April 17. Temperature treatments affected the onset of laying differently for early- and latelaid birds (early-laid birds had a mother that laid early). Cold conditions in February or March, followed by a temperature rise, made early-laid females lay significantly earlier than early-laid females in constant warm conditions or early-laid females that experienced a cold period in April with no subsequent temperature rise. In contrast, cold conditions in February or March, followed by a temperature rise, made late-laid females lay significantly later (table $1 a$; fig. $1 B, 1 C$ ). In the model using realized temperatures as a time-dependent variable, the small value of the weighting factor $(\alpha=0.04)$ indicated a long-term temperature integration to be appropriate. This long-term pattern especially influenced the laying decision of latelaid females: overall cold conditions induced an advance and warm conditions a delay. In contrast, early-laid fe- males did not change their laying date in response to longterm temperature (table $1 b$ ).

In 2009, when the effect of daily temperature variation was tested, 27 pairs initiated at least one clutch, starting on April 15. Neither temperature treatment nor realized temperature influenced the onset of laying (table 1; fig. $1 E, 1 F)$. Note that in this setup, daily means did not distinguish between high- and low-daily-amplitude treatments, except for variation between aviaries. An analysis comparing minimum temperatures also failed to show any temperature effect on laying date (data not presented). The onset of laying in early- and late-laid females was not influenced by whether they were paired with males from either late- or early-laying families (pair composition; table $1)$.

In 2010, when the effect of temperature-increase patterns in early and late spring was tested, 18 pairs initiated at least one clutch, starting on April 23, about 2 weeks after the last increase in temperature. The onset of reproduction was determined by the temperature rise shortly before laying: an earlier rise in late spring led to earlier laying, independent of the temperature pattern in early

Table 1: Effects of temperature treatment, or realized temperature, and individual traits on the onset of reproduction

\begin{tabular}{|c|c|c|c|c|c|c|c|c|c|}
\hline & \multicolumn{3}{|c|}{2008} & \multicolumn{3}{|c|}{2009} & \multicolumn{3}{|c|}{2010} \\
\hline & $\chi^{2}$ & df & $P$ & $\chi^{2}$ & df & $P$ & $\chi^{2}$ & df & $P$ \\
\hline \multicolumn{10}{|l|}{ a. Temperature treatment and individual traits: } \\
\hline Temperature treatment & 23.80 & 3 & $<.001^{\star *}$ & 4.52 & 3 & .21 & 15.89 & 3 & $.001^{\star *}$ \\
\hline Laying date of female's mother & & & & .67 & 1 & .41 & 3.81 & 1 & .051 \\
\hline Treatment $\times$ laying date of female's mother & 24.67 & 1 & $<.001^{\star *}$ & 2.04 & 1 & .15 & 1.60 & 1 & .21 \\
\hline Laying date of male's mother & 1.79 & 1 & .17 & .01 & 1 & .91 & 10.62 & 1 & $.003^{\star *}$ \\
\hline Female personality & 12.28 & 1 & $.005^{\star *}$ & 3.36 & 1 & .081 & 10.43 & 1 & $.004^{\star *}$ \\
\hline Female chick weight & 5.06 & 1 & $.003^{\star *}$ & .81 & 1 & .38 & 2.37 & 1 & .12 \\
\hline Male personality & 1.76 & 1 & $.010^{\star}$ & .75 & 1 & .41 & 12.68 & 1 & $.003^{\star *}$ \\
\hline Male chick weight & 3.46 & 1 & .081 & .12 & 1 & .72 & 7.84 & 1 & $.010^{\star}$ \\
\hline Pair composition & & & & 6.88 & 3 & .076 & & & \\
\hline \multicolumn{10}{|l|}{$b$. Realized temperature and individual traits: } \\
\hline Realized temperature & 2.27 & 1 & .13 & .57 & 1 & .57 & 5.46 & 1 & $.012^{\star}$ \\
\hline Laying date of female's mother & 5.48 & 1 & $.019^{*}$ & .67 & 1 & .41 & .88 & 1 & .37 \\
\hline Temperature $\times$ laying date of female's mother & 6.11 & 1 & $.010^{*}$ & .21 & 1 & .65 & .52 & 1 & .40 \\
\hline Temperature $\times$ photoperiod & .17 & 1 & .68 & 3.82 & 1 & .051 & 1.40 & 1 & .25 \\
\hline Laying date of male's mother & .25 & 1 & .62 & 1.28 & 1 & .26 & .13 & 1 & .71 \\
\hline Female personality & .46 & 1 & .50 & 3.36 & 1 & .081 & .73 & 1 & .36 \\
\hline Female chick weight & .48 & 1 & .49 & 1.80 & 1 & .19 & 5.17 & 1 & $.015^{\star}$ \\
\hline Male personality & .01 & 1 & .93 & 3.10 & 1 & .11 & .62 & 1 & .57 \\
\hline Male chick weight & .24 & 1 & .63 & .11 & 1 & .74 & $<.01$ & 1 & .96 \\
\hline Pair composition & & & & 6.88 & 3 & .076 & & & \\
\hline Best weighing factor $\alpha$ & \multicolumn{3}{|c|}{.04} & \multicolumn{3}{|c|}{.01} & \multicolumn{3}{|c|}{.14} \\
\hline
\end{tabular}

Note: We tested how the onset of reproduction in 2008-2010 was affected by temperature treatments $(a)$ or realized temperatures and individual traits $(b)$. The best weighting factor $\alpha$ is given in the "df" column for each year. Female family was fitted as a random effect. Statistics are given for the point of exclusion from the model. In case of significant interactions, statistics for the components are given in the presence of the interaction. Therefore, statistics for a continuous variable cannot be provided for an interaction of this variable and a factor.

${ }^{*} P<.05$.

** $P<.01$ 


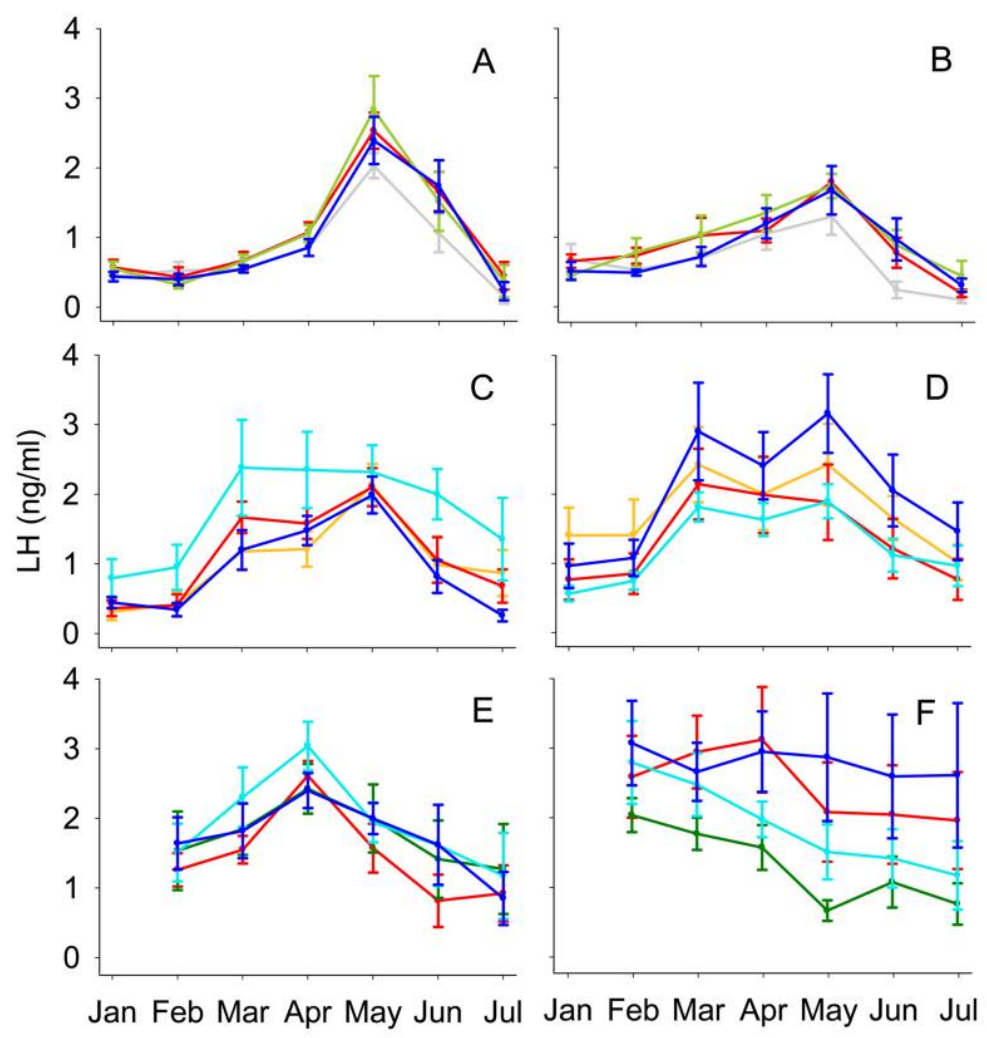

Figure 2: Changes in the concentration of plasma luteinizing hormone (LH) in females (left) and males (right) for the years 2008 (A, B), $2009(C, D)$, and $2010(E, F)$. Birds were exposed to temperature treatments shown in figure 1, with the same color coding. Means \pm standard errors are shown.

spring (table $1 a$; fig. $1 H, 1 I$ ). The weighting factor for the best time-dependent temperature variable was fairly large $(\alpha=0.14)$, indicating that the laying date in this year was based on recently experienced temperatures. Overall colder spring conditions advanced the start of laying (table $1 b$ ).

To test for genetic effects on timing, we compared laying dates, after controlling for temperature treatment, within and across families. In 2009 and 2010, females from the same family had similar laying dates (female family: 2009: $\left.\chi_{14}^{2}=26.84, P=.02 ; 2010: \chi_{8}^{2}=21.98, P=.005\right)$, while in 2008 and 2010 there was a similarity of females mated to brothers (male family: 2008: $\chi_{11}^{2}=34.39, P<.001$; 2010: $\left.\chi_{10}^{2}=30.03, P<.001\right)$.

\section{Termination of Reproduction}

Data on the termination of reproduction are presented in appendix A, available online. In summary, only the temperature development late in spring played a role in the termination of laying. Comparably to the onset of reproduction, early- and late-laid females reacted differently to temperature cues. In all years there was a consistent resemblance between sisters, suggesting a strong genetic component $\left(2008: \chi_{10}^{2}=30.25, P<.001 ; 2009: \chi_{14}^{2}=\right.$ 29.15, $\left.P=.010 ; 2010: \chi_{8}^{2}=16.52, P=.036\right)$.

\section{Additional Effects of Individual Characteristics}

In 2008, high novelty-seeking behavior and higher female chick weights induced earlier laying in adults, while in 2010 laying was delayed by high novelty-seeking behavior and also when females had a partner that was an earlylaid or light chick (table 1a). In models using realized temperature, females that had been heavier chicks laid later in 2010 (table 1b). Because of inconsistency, these observations are deemed not to be biologically meaningful.

\section{Luteinizing Hormone (LH)}

Female LH plasma concentrations increased over spring in all years, peaking in April/May (fig. 2A, 2C, 2E). The same distinct seasonal peak was found in males in 2008 . 
However, males in 2009 had a wider peak, while in 2010 males reached maximum concentrations in early spring (fig. 2B, 2D, 2F). Temperature treatment did not influence LH concentrations, except in 2009, when females experiencing a narrow temperature variation around a low mean tended to have elevated levels (table 2). Temperature treatments affected early- and late-laid males differently in 2009: early-laid males experiencing warm temperatures and a wide variation had lower LH concentrations than late-laid males in all treatments (table 2). In 2009, low novelty-seeking behavior was correlated with low LH concentrations (table 2), also observable as a trend in males of 2008 .

\section{Gonadal Development}

The largest ovarian follicles grew exponentially over time, but temperature treatments had no effect on their size in any year (table $3 a$; fig. 3 ). In 2010, early-laid females grew their follicles faster than late-laid females (table $3 a$ ).

Testis sizes followed a typical pattern of steep recrudescence, peaking in April, and subsequent regression. Testis maturation was independent of temperature treatment in any given year (table 3b; fig. 3). However, in 2008, gonadal regression was delayed in males that experienced a cold period compared to that in males under a constant warm temperature (table $3 c$; fig. $3 B$ ). In addition, in some months the rate of testis regression differed between earlyand late-laid males (table 3), but not in a consistent pattern.

\section{Onset and Duration of Molt}

Molt data are presented in appendix B, available online. In most years, nonlaying birds started molt significantly earlier than laying pairs. In general, the later a bird stopped reproducing, the later it started molting. There was no effect of temperature treatment on the onset of molt. Some birds experiencing a cold spring period in 2008 molted significantly faster, even though molt took place under constant warm conditions.

\section{Discussion}

Our studies are among the first to investigate how spring temperature patterns affect laying dates under controlled conditions. We show clearly that, despite previous assumptions, warm temperatures alone do not accelerate the onset of laying in great tits. In 2008, females that experienced a constant warm spring did not, on average, lay earlier than birds exposed to a cold period. In 2009, irrespective of the daily amplitude around the mean, females kept under a high average temperature did not lay earlier

Table 2: Effects of temperature treatment and individual traits on luteinizing hormone (LH) development

\begin{tabular}{|c|c|c|c|c|c|c|c|c|c|}
\hline & \multicolumn{3}{|c|}{2008} & \multicolumn{3}{|c|}{2009} & \multicolumn{3}{|c|}{2010} \\
\hline & $\chi^{2}$ & $\mathrm{df}$ & $P$ & $\chi^{2}$ & df & $P$ & $\chi^{2}$ & $\mathrm{df}$ & $P$ \\
\hline \multicolumn{10}{|l|}{ a. LH $(\log )$ females: } \\
\hline Temperature treatment & 3.18 & 3 & .36 & 7.64 & 3 & .054 & 1.61 & 3 & .66 \\
\hline Month & 219.3 & 6 & $<.001^{\star *}$ & 165.2 & 6 & $<.001^{\star *}$ & 110.9 & 5 & $<.001^{\star *}$ \\
\hline Treatment $\times$ month & 15.11 & 3 & .65 & 19.76 & 3 & .35 & 10.21 & 3 & .81 \\
\hline Laying date of female's mother & .70 & 1 & .40 & $<.01$ & 1 & 1 & 3.35 & 1 & .067 \\
\hline Treatment $\times$ laying date of female's mother & .95 & 3 & .81 & 1.79 & 3 & .62 & .56 & 3 & .91 \\
\hline Laying date of male's mother & 1.19 & 1 & .27 & .06 & 1 & .81 & .72 & 1 & .40 \\
\hline Personality female & .76 & 1 & .38 & 5.18 & 1 & $.023^{\star}$ & .40 & 1 & .53 \\
\hline \multicolumn{10}{|l|}{ b. LH (log) males: } \\
\hline Temperature treatment & 4.47 & 3 & .21 & 18.3 & 3 & $<.001^{\star *}$ & 1.71 & 3 & .64 \\
\hline Month & 155.2 & 6 & $<.001^{\star \star}$ & 171.0 & 6 & $<.001^{\star \star}$ & 85.32 & 5 & $<.001^{\star \star}$ \\
\hline Treatment $\times$ month & 25.07 & 3 & .12 & 22.48 & 3 & .21 & 9.59 & 3 & .84 \\
\hline Laying date of male's mother & $<.01$ & 1 & 1 & & & & $<.01$ & 1 & 1 \\
\hline Treatment $\times$ laying date of male's mother & 1.22 & 3 & .75 & 15.40 & 3 & $.002^{\star \star}$ & 1.45 & 3 & 69 \\
\hline Laying date of female's mother & .15 & 1 & .70 & .77 & 1 & .38 & .36 & 1 & .55 \\
\hline Personality male & 3.63 & 1 & .057 & 4.05 & 1 & $.044^{*}$ & 1.15 & 1 & .28 \\
\hline
\end{tabular}

Note: Hormonal development between January and July 2008-2010 (not containing January 2010) in females $(a)$ and males $(b)$ was log transformed. Individual and family were fitted as random effects. Statistics are given for the point of exclusion from the model. In case of significant interactions, statistics for the components are given in the presence of the interaction. Therefore, statistics for a continuous variable cannot be provided for an interaction of this variable and a factor.

${ }^{*} P<.05$.

${ }^{* *} P<.01$ 
Table 3: Effects of temperature treatment and individual traits on gonadal development

\begin{tabular}{|c|c|c|c|c|c|c|c|c|c|}
\hline & \multicolumn{3}{|c|}{2008} & \multicolumn{3}{|c|}{2009} & \multicolumn{3}{|c|}{2010} \\
\hline & $\chi^{2}$ & df & $P$ & $\chi^{2}$ & $\mathrm{df}$ & $P$ & $\chi^{2}$ & df & $P$ \\
\hline \multicolumn{10}{|l|}{ a. Follicle volume, January-April (log): } \\
\hline Temperature treatment & .50 & 3 & .92 & 2.60 & 3 & .46 & 3.65 & 3 & .30 \\
\hline Laying date of female's mother & 2.36 & 1 & .12 & .26 & 1 & .61 & 9.22 & 1 & $.002^{\star x}$ \\
\hline Treatment $\times$ laying date of female's mother & 4.19 & 3 & .24 & 2.51 & 3 & .47 & 1.46 & 3 & .69 \\
\hline Tarsus female & 1.03 & 1 & .31 & 1.55 & 1 & .21 & .18 & 1 & .67 \\
\hline Month & 261.2 & 1 & $<.001^{\star *}$ & 97.71 & 1 & $<.001^{\star \star}$ & 123.2 & 1 & $<.001^{\star x}$ \\
\hline \multicolumn{10}{|l|}{ b. Testis volume, January-April (log): } \\
\hline Temperature treatment & 2.35 & 3 & .50 & 2.61 & 3 & .46 & .44 & 3 & .93 \\
\hline Laying date of male's mother & .01 & 1 & .94 & $<.01$ & 1 & 1 & $<.01$ & 1 & 1 \\
\hline Treatment $\times$ laying date of male's mother & .80 & 3 & .85 & 3.11 & 3 & .38 & .25 & 3 & .97 \\
\hline Tarsus female & 3.21 & 1 & .073 & .66 & 1 & .42 & 2.66 & 1 & .10 \\
\hline Month & 317.3 & 1 & $<.001^{* *}$ & 268.4 & 1 & $<.001^{* *}$ & 161.8 & 1 & $<.001^{\star x}$ \\
\hline \multicolumn{10}{|l|}{ c. Testis volume, May: } \\
\hline Temperature treatment & 9.41 & 3 & $.024^{\star}$ & 5.05 & 3 & .17 & 1.10 & 3 & .78 \\
\hline Laying date of male's mother & .52 & 1 & .47 & 5.31 & 1 & $.021^{\star}$ & .06 & 1 & .80 \\
\hline Treatment $\times$ laying date of male's mother & 1.76 & 3 & .62 & 4.88 & 3 & .18 & .37 & 3 & .95 \\
\hline \multicolumn{10}{|l|}{ d. Testis volume, June: } \\
\hline Temperature treatment & 3.71 & 3 & .29 & 9.28 & 3 & $.026^{*}$ & 3.57 & 3 & .31 \\
\hline Laying date of male's mother & 4.06 & 1 & $.044^{*}$ & & & & 1.11 & 1 & .29 \\
\hline Treatment $\times$ laying date of male's mother & 6.70 & 3 & .082 & 8.45 & 3 & $.038^{*}$ & 2.16 & 3 & .54 \\
\hline \multicolumn{10}{|l|}{ e. Testis volume, July: } \\
\hline Temperature treatment & 5.75 & 3 & .12 & 5.04 & 3 & .17 & 4.03 & 3 & .26 \\
\hline Laying date of male's mother & 2.38 & 1 & .12 & $<.01$ & 1 & 1 & 6.96 & 1 & $.008^{\star x}$ \\
\hline Treatment $\times$ laying date of male's mother & 3.00 & 3 & .39 & 4.56 & 3 & .21 & 2.88 & 3 & .41 \\
\hline
\end{tabular}

Note: Gonadal recrudescence for females $(a)$ and males $(b)$ between January and April 2008-2010 (not containing April 2009 for females and January 2010 for both sexes) was log transformed. Testicular volume in May, June, and July was analyzed in separate models ( $c-e$, respectively). Individual (in the case of gonadal recrudescence) and family were fitted as random effects. Statistics are given for the point of exclusion from the model. In case of significant interactions, statistics for the components are given in the presence of the interaction. Therefore, statistics for a continuous variable cannot be provided for an interaction of this variable and a factor.

${ }^{*} P<.05$.

** $P<.01$

than females kept under a low temperature. In 2010, females that experienced a fast and warm early spring (green and red lines in fig. $1 G$ ) did not lay earlier overall than females that experienced a slow and colder spring (blue lines in fig. $1 G$ ). The lack of an advancing effect of higher mean temperature is in accordance with the results of Visser et al. (2011), who did not find a difference in laying dates between females from cold and warm treatments that experienced a similar progressive increase in temperature. As it is well known that birds in the wild (e.g., Cresswell and McCleery 2003; Both et al. 2004) and in captivity (Visser et al. 2009) do lay earlier under natural temperature patterns of warm years, the key question is to which component of the patterns of change birds respond.

Our results clearly suggest that the relevant information resides in the periods of increasing temperature. In 2008, exposure to a temperature increase at the end of February or March advanced the onset of laying in genetic early layers and delayed it in genetic late layers, compared to that in females in other treatments. This shows that birds are sensitive to an increase in temperature well in advance of laying; this is also indicated by the best integratedtemperature variable, which shows a long-term integration of temperature to be relevant for the laying decision. In 2010, a temperature increase close to the laying period advanced laying, independently of the temperature pattern in early spring. Similar to 2008 , an overall warmer spring even delayed laying in 2010. The relevance of more recent temperatures was also reflected in the choice of the best integrated-temperature variable. The importance of a temperature rise close to laying resembles findings by Meijer et al. (1999), who observed that pairs of starlings (Sturnus vulgaris) kept in groups in climate chambers started laying about a week after a $5^{\circ} \mathrm{C}$ temperature increase at different dates in April.

These observations show that the weight given to specific temperature cues changes over spring and that these cues are interpreted differently by birds with different ge- 

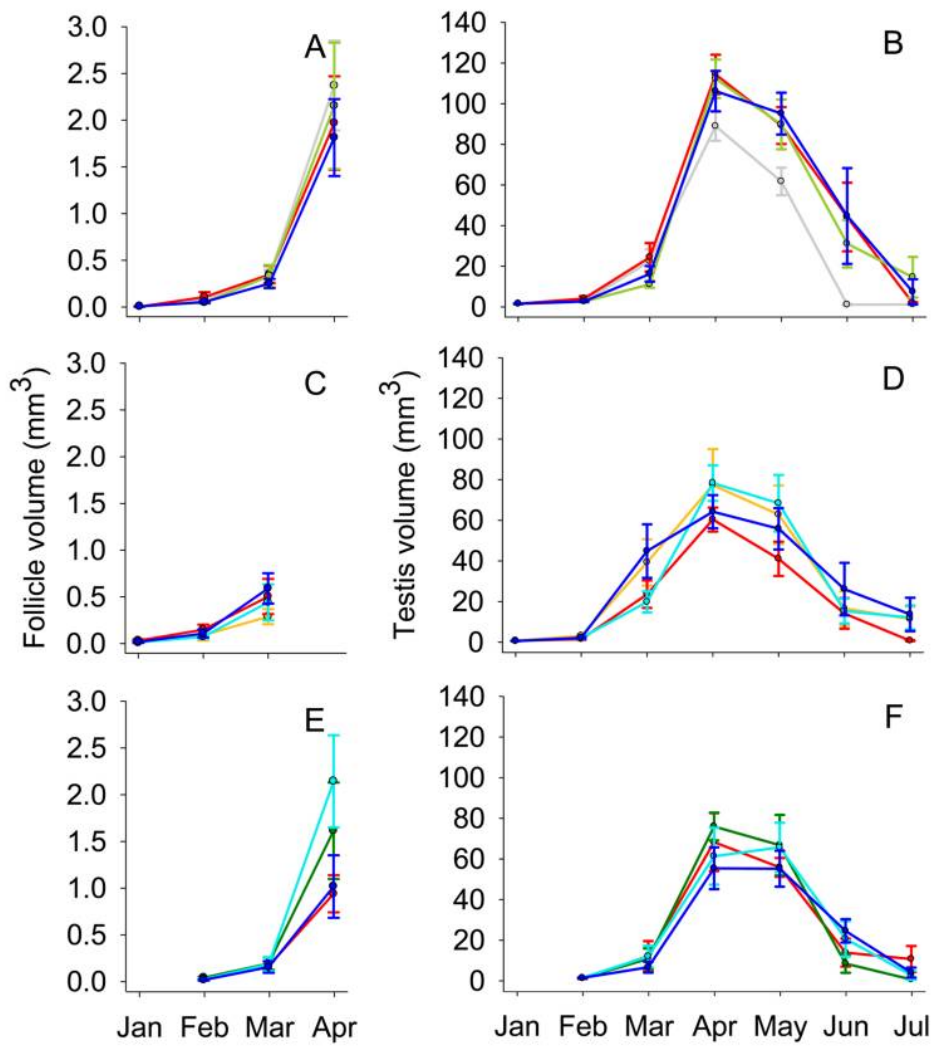

Figure 3: Growth of the largest ovarian follicle in females (left) and the left testis in males (right) for years $2008(A, B), 2009(C, D)$, and $2010(E, F)$. Birds were exposed to temperature treatments shown in figure 1, with the same color coding. Means \pm standard errors are shown.

netic backgrounds. There is no universal answer to the question of which spring-period changes in temperature have the largest effect on the laying date, as this depends on the nature of the temperature pattern. Results from 2008 and 2010 show that around March, an increase in spring temperatures to a moderate level advances the onset of laying, especially for birds from early-laying families. A moderate increase at this time, not rising too high, might be recognized as an indication of a long season, with conditions adequate to allow for more than one breeding attempt. Early-laying females could therefore try to raise their first clutch in advance of the food peak, increasing their chances of raising a second brood as well (Crick et al. 1993; Verboven and Verhulst 1996). We know that in our population more pairs produce a second brood in colder years (Husby et al. 2009); however, patterns of temperature increase have not been assessed in this respect yet. Late-laying females also respond to a temperature increase around March but delay their reproduction. This could mean that they try to synchronize their only breeding attempt with the later-anticipated food peak. In 2010, a second temperature increase close to the laying period had an advancing influence on the onset of laying in both early- and late-laid females. In combination, these results demonstrate that birds that experience a temperature rise in early spring up to moderate temperatures lay early if they are from an early-laying family but that this genetic disposition can be overruled by a temperature increase close to laying, which induces early laying in all birds. It seems plausible that temperature cues can affect different developmental stages and that the implication of such cues, as well as the intensity of a behavioral response, changes over time (Wingfield 2008).

In addition, we can exclude the possibility that birds integrate temperature cues for the initiation of laying as the experienced daily temperature range. Furthermore, a clear difference in minimum night temperature, an important factor restricting invertebrate development, did not affect laying dates in 2009.

The use of siblings allowed us to investigate genetic or early environmental effects on the timing of reproduction. In two years, sisters resembled each other in their laying 
date more than did unrelated females, which is consistent with an earlier study showing that temperature sensitivity in great tits depends on genotype (Visser et al. 2011). In addition, laying dates in 2009 were closely correlated with laying dates recorded one year later by the same pairs in open aviaries (Schaper et al. 2011). Visser et al. (2009) also found a high repeatability in the distribution of laying dates of females breeding both in climate-controlled aviaries and in the wild. This consistency points to a similarity in the physiological setup of related females that leads to a certain timing of laying. That timing of reproduction has a heritable component is known for a number of species (Prendergast et al. 2004; Brommer et al. 2005; Nussey et al. 2005; Gienapp et al. 2006). If a large part of the response mechanism to environmental cues is determined by genetic differences, then the maintenance of diversity in these mechanisms indicates that they do equally well over a large number of years. Adaptations in the way cues are both perceived and physiologically transduced into behavioral responses should be further investigated.

In 2009, "mixed pairs," for example, early-family female-late-family male, were formed to decouple genetic dispositions. In that year, we found no support for indirect genetic effects (Brommer and Rattiste 2008; Visser et al. 2011), that is, no male family effect and no clear influence of the pair composition.

Further, we cannot conclude that females that experienced good conditions as nestlings show carryover effects and lay early. In addition, even though social cues are certainly an important component of the laying decision (Helm et al. 2006), it is not apparent that males with a high personality score, which are more active singers (Naguib et al. 2010), induce their mates to lay early.

The termination of reproduction determines the earliest possible time to start molt and thus relates to energy partitioning and condition over winter. As temperature is indicative of the rate at which prey availability declines, it should affect the decision to stop laying, which we confirmed here. We found a consistent resemblance between sisters in the termination of laying in all years, possibly showing genetic differences in temperature sensitivity between early- and late-laying families, as these varied in termination dates in response to temperature. These intriguing results support similar findings by Visser et al. (2011).

The timing of the rise in plasma luteinizing hormone (LH) concentration and gonadal maturation did not differ between birds that were exposed to diverse spring temperature patterns. This confirms that early stages of the reproductive cycle are not fine-tuned by temperature cues (Caro and Visser 2009). Despite a number of well-designed experiments, there is still conflicting evidence about temperature effects on reproductive physiology (e.g., Suom- alainen 1937; Storey and Nicholls 1982; Silverin and Viebke 1994; Wingfield et al. 1996, 1997, 2003; Dawson 2005a; Perfito et al. 2005; Caro et al. 2009). At temperate latitudes, the timing of gonadal growth seems to be predominantly controlled by photoperiod. Therefore, in great tits a substantial advancement of laying due to benign spring conditions could be constrained by the functionality of the female reproductive system, setting an earliest possible laying date relative to the lengthening photoperiod. However, because the decision to lay itself is fine-tuned by the rise in temperature over the season, this points toward an unknown neuroendocrine mechanism, not reflected in gonadal development, that mediates the integration of temperature cues at the time of gonadal development and is involved in the laying decision. Because wild birds are exposed to a suite of interrelated cues, gonadal development is possibly fine-tuned by nontemperature cues.

Testis regression overall was not affected by temperature. However, it was advanced by a constant warm spring in 2008 , even though the temperature difference of $8^{\circ} \mathrm{C}$ was small relative to that in other studies. That constant warm temperatures induce early regression (Silverin and Viebke 1994; Dawson 2005a; Silverin et al. 2008; Visser et al. 2011) and that very low temperatures delay it (Jones 1986) are well documented, but possible mechanisms are still debated. High concentrations of prolactin are associated with gonadal regression and the start of molt (Dawson and Sharp 1998), and some studies have suggested that high temperatures may enhance prolactin secretion (Maney et al. 1999; Gahali et al. 2001). However, recent studies have shown no evidence for this (Dawson and Sharp 2010; Visser et al. 2011). Why differences in the timing of regression were observed only in 2008 is unclear, but constant temperatures might be a reason. Remarkably, even a cold period in February/March prolonged testis function, suggesting again the involvement of an elusive neuroendocrine signal that transduces temperature information toward later life-cycle stages.

Temperatures experienced in spring, as well as moderate temperature differences during the molting period itself, do not play a relevant role in the timing of postnuptial molt in great tits. In contrast, our results underline the importance of the termination of reproduction in influencing later life-cycle stages.

\section{Concluding Remarks}

Experiments on direct temperature effects on the timing of avian reproduction have produced ambiguous results, reflecting the complexity of the decision-making process. Our results show that an overall warmer spring by no 
means leads to an earlier onset of breeding but that it is rather the temperature increase that is used as a cue by female great tits to time their onset of laying. The mechanisms involved remain to be established. We therefore encourage further experiments under controlled conditions that take into account temperature variation, but we also encourage a reevaluation of temperature patterns preceding the breeding season and possible correlations with laying dates in long-term-studied wild populations.

Our results further indicate that birds from different genetic backgrounds react differently to temperature cues in early and late spring. It has yet to be determined in what aspects these families differ. Environmental information that produces plasticity in laying has to be received, processed, and integrated into a decision, a process mediated by the neuroendocrine system (Ball and Balthazart 2002; Lessells 2008; Lyon et al. 2008). The variation on which selection can act has to be genetic variation in (a combination of) underlying mechanisms (Wingfield et al. 2008; Bourgault et al. 2010; Visser et al. 2010a). We still know too little about how and where temperature cues are integrated, in contrast to photoperiodic cues (Sharp 2005). We found no evidence that early stages of reproductive development were affected by spring temperature, which indicates that a so-far-unconsidered pathway, such as the hypothalamo-pituitary-thyroid axis (Wada 1993; Wingfield et al. 2003; Chastel et al. 2003), or a synergism involving multiple signals could be responsible for conveying the information that ultimately induces laying. However, to elicit an organized physiological response $\rightarrow$ supplementary cues, such as temperature patterns, presumably have to converge on the gonadotropin-releasing hormone system (Ball 1993; Hau 2001).

Climate change is affecting living systems in complex ways (Parmesan and Yohe 2003), and studies on phenology become increasingly relevant in this framework (Peñuelas and Filella 2001), as the initiation of life-history traits anc the overall development of biological systems are highly temperature dependent (Parmesan and Yohe 2003; Root et al. 2003). In our study system, the relationship between food availability in spring and environmental cues usecfor timing of reproduction has shifted as a result of climate change, and great tits, as well as other small passerines appear to be unable to compensate for this mismatch by adjusting their time of breeding (Visser et al. 1998; Both et al. 2004; Coppack and Pulido 2004). Our experiments offer insights into the scope of individual variation in response to temperature cues as well as into the genetic basis underlying it, which is crucial for natural selection to restore the synchrony of timing of reproduction with th $\rightarrow$ altered phenology of environmental conditions.

\section{Acknowledgments}

We thank the board of the Hoge Veluwe National Park for allowing us to work in their area. We are grateful to the late Leonard Holleman and to T. Durmaz and H. Wiggers for assistance in the aviaries, C. Mateman for the determination of sex and extrapair paternity, K. van Oers for help on personality scores, M. Aaldering and F. Petit for taking good care of all the birds, and A. and G. Wijlhuizen for technical support. We also thank two anonymous reviewers for their constructive comments. M.E.V. was supported by a Netherlands Organisation for Scientific Research (NWO) Vici grant, S.P.C. by an NWO Veni grant and a Wallonia-Brussels International World grant, and P.J.S. by the Roslin Institute. Experiments were carried out under licences CTO.0501, CTE.0809, and CTE.0907 of the Animal Experimentation Committee of the Royal Dutch Academy of Sciences (DEC-KNAW).

\section{Literature Cited}

Ball, G. F. 1993. The neural integration of environmental information by seasonally breeding birds. American Zoologist 33:185-199.

Ball, G. F., and J. Balthazart. 2002. Neuroendocrine mechanisms regulating reproductive cycles and reproductive behavior in birds. Pages $649-798$ in D. W. Pfaff, A. P. Arnold, A. M. Etgen, S. E. Fahrbach, and R. T. Rubin, eds. Hormones, brain and behavior. Academic Press, San Diego, CA.

Bauer, S., P. Gienapp, and J. Madsen. 2008. The relevance of environmental conditions for departure decision changes en route in migrating geese. Ecology 89:1953-1960.

Both, C., A. V. Artemyev, B. Blaauw, R. J. Cowie, A. J. Dekhuijzen, T. Eeva, A. Enemar, et al. 2004. Large-scale geographical variation confirms that climate change causes birds to lay earlier. Proceedings of the Royal Society B: Biological Sciences 271:1657-1662.

$\rightarrow$ Bourgault, P., D. Thomas, P. Perret, and J. Blondel. 2010. Spring vegetation phenology is a robust predictor of breeding date across broad landscapes: a multi-site approach using the Corsican blue tit (Cyanistes caeruleus). Oecologia (Berlin) 162:885-892.

$\rightarrow$ Brommer, J. E., and K. Rattiste. 2008. "Hidden" reproductive conflict between mates in a wild bird population. Evolution 62:2326-2333.

Brommer, J. E., J. Merilä, B. C. Sheldon, and L. Gustafsson. 2005. Natural selection and genetic variation for reproductive reaction norms in a wild bird population. Evolution 59:1362-1371.

Caro, S. P., and M. E. Visser. 2009. Temperature-induced elevation of basal metabolic rate does not affect testis growth in great tits. Journal of Experimental Biology 212:1994-1998.

$\rightarrow$ Caro, S. P., M. M. Lambrechts, O. Chastel, P. J. Sharp, D. W. Thomas, and J. Balthazart. 2006. Simultaneous pituitary-gonadal recrudescence in two Corsican populations of male blue tits with asynchronous breeding dates. Hormones and Behavior 50:347-360.

Caro, S. P., M. M. Lambrechts, J. Balthazart, and P. Perret. 2007. Non-photoperiodic factors and timing of breeding in blue tits: impact of environmental and social influences in semi-natural conditions. Behavioural Processes 75:1-7.

Caro, S. P., A. Charmantier, M. M. Lambrechts, J. Blondel, J. Balthazart, and T. D. Williams. 2009. Local adaptation of timing of 
reproduction: females are in the driver's seat. Functional Ecology 23:172-179.

$\rightarrow$ Charmantier, A., R. H. McCleery, L. R. Cole, C. Perrins, L. E. B $\rightarrow$ Kruuk, and B. C. Sheldon. 2008. Adaptive phenotypic plasticity in response to climate change in a wild bird population. Science 320:800-803.

$\rightarrow$ Chastel, O., A. Lacroix, and M. Kersten. 2003. Pre-breeding energy requirements: thyroid hormone, metabolism and the timing of reproduction in house sparrows Passer domesticus. Journal of Aviar $\rightarrow$ Biology 34:298-306.

Coppack, T., and F. Pulido. 2004. Photoperiodic response and the adaptability of avian life cycles to environmental change. Page 131-150 in A. P. Møller, W. Fielder, and P. Berthold, eds. Birds and climate change. Advances in Ecological Research. Academic Press, London.

$\rightarrow$ Cox, D. R. 1972. Regression models and life-tables. Journal of the Royal Statistical Society B: Statistical Methodology 34:187-220.

$\rightarrow$ Cresswell, W., and R. McCleery. 2003. How great tits maintain synchronization of their hatch date with food supply in response tc long-term variability in temperature. Journal of Animal Ecology 72:356-366.

$\rightarrow$ Crick, H. Q. P., D. W. Gibbons, and R. D. Magrath. 1993. Seasona' changes in clutch size in British birds. Journal of Animal Ecology 62:263-273.

$\rightarrow$ Crick, H. Q. P., C. Dudley, D. E. Glue, and D. L. Thomson. 1997 UK birds are laying eggs earlier. Nature 388:526.

$\rightarrow$ Dawson, A. 2005a. The effect of temperature on photoperiodically regulated gonadal maturation, regression and moult in starlings: potential consequences of climate change. Functional Ecology 19. 995-1000.

$\rightarrow$. 2005b. The scaling of primary flight feather length and mass in relation to wing shape, function and habitat. Ibis 147:283-292.

$\rightarrow$ - 2008. Control of the annual cycle in birds: endocrine constraints and plasticity in response to ecological variability. Philosophical Transactions of the Royal Society B: Biological Sciences 363:1621-1633.

$\rightarrow$ Dawson, A., and I. Newton. 2004. Use and validation of a molt score index corrected for primary feather mass. Auk 121:372-379.

$\rightarrow$ Dawson, A., and P. J. Sharp. 1998. The role of prolactin in the development of reproductive photorefractoriness and postnuptial molt in the European starling (Sturnus vulgaris). Endocrinology 139:485-490.

$\rightarrow-2010$. Seasonal changes in concentrations of plasma LH anc prolactin associated with the advance in the development of photorefractoriness and molt by high temperature in the starling. General and Comparative Endocrinology 167:122-127.

$\rightarrow$ Dawson, A., V. M. King, G. E. Bentley, and G. F. Ball. 2001. Photoperiodic control of seasonality in birds. Journal of Biological Rhythms 16:365-380.

$\rightarrow$ Dingemanse, N. J., C. Both, P. J. Drent, K. van Oers, and A. J. van Noordwijk. 2002. Repeatability and heritability of exploratory behaviour in great tits from the wild. Animal Behaviour 64:929-938.

$\rightarrow$ Drent, P. J., K. van Oers, and A. J. van Noordwijk. 2003. Realized heritability of personalities in the great tit (Parus major). Pro ceedings of the Royal Society B: Biological Sciences 270:45-51.

$\rightarrow$ Gahali, K., M. E. El Halawani, and I. Rozenboim. 2001. Photostim $\rightarrow$ ulated prolactin release in the turkey hen: effect of ovariectomy and environmental temperature. General and Comparative Endocrinology 124:166-172.

$\rightarrow$ Gienapp, P., L. Hemerik, and M. E. Visser. 2005. A new statistica $\rightarrow$ Meijer, T., U. Nienaber, U. Langer, and F. Trillmich. 1999. Temper- tool to predict phenology under climate change scenarios. Global Change Biology 11:600-606.

Gienapp, P., E. Postma, and M. E. Visser. 2006. Why breeding time has not responded to selection for earlier breeding in a songbird population. Evolution 60:2381-2388.

$\rightarrow$ Gienapp, P., R. A. Väisänen, and J. E. Brommer. 2010. Latitudinal variation in breeding time reaction norms in a passerine bird. Journal of Animal Ecology 79:836-842.

Grieco, F., A. J. van Noordwijk, and M. E. Visser. 2002. Evidence for the effect of learning on timing of reproduction in blue tits. Science 296:136-138.

Griffiths, R., M. C. Double, K. Orr, and R. J. G. Dawson. 1998. A DNA test to sex most birds. Molecular Ecology 7:1071-1075.

Gwinner, E. 1986. Circannual rhythms. Springer, Berlin.

- 1996. Circannual clocks in avian reproduction and migration. Ibis $138: 47-63$.

Hau, M. 2001. Timing of breeding in variable environments: tropical birds as model systems. Hormones and Behavior 40:281-290.

Hau, M., M. Wikelski, and J. C. Wingfield. 2000. Visual and nutritional food cues fine-tune timing of reproduction in a Neotropical rainforest bird. Journal of Experimental Zoology 286:494-504.

Helm, B., T. Piersma, and H. van der Jeugd. 2006. Sociable schedules: interplay between avian seasonal and social behaviour. Animal Behaviour 72:245-262.

Husby, A., L. E. B. Kruuk, and M. E. Visser. 2009. Decline in the frequency and benefits of multiple brooding in great tits as a consequence of a changing environment. Proceedings of the Royal Society B: Biological Sciences 276:1845-1854.

Jones, L. R. 1986. The effect of photoperiod and temperature on testicular growth in captive black-billed magpies. Condor 88:9193.

Kalbfleisch, J. D., and R. L. Prentice. 2002. The statistical analysis of failure time data. Wiley, New York.

Kluyver, H. N. 1952. Notes on body weight and time of breeding in the great tit, Parus m. major L. Ardea 40:123-141.

Lack, D. 1968. Ecological adaptations for breeding in birds. Methuen, London.

Lambrechts, M. M., and P. Perret. 2000. A long photoperiod overrides non-photoperiodic factors in blue tits' timing of reproduction. Proceedings of the Royal Society B: Biological Sciences 267:585588.

Lessells, C. M. 2008. Neuroendocrine control of life histories: what do we need to know to understand the evolution of phenotypic plasticity? Philosophical Transactions of the Royal Society B: Biological Sciences 363:1589-1598.

Lyon, B. E., A. S. Chaine, and D. W. Winkler. 2008. Ecology: a matter of timing. Science 321:1051-1052.

$\rightarrow$ Maney, D. L., T. P. Hahn, S. J. Schoech, P. J. Sharp, M. L. Morton, and J. C. Wingfield. 1999. Effects of ambient temperature on photo-induced prolactin secretion in three subspecies of whitecrowned sparrow, Zonotrichia leucophrys. General and Comparative Endocrinology 113:445-456.

$\rightarrow$ McCleery, R. H., and C. M. Perrins. 1998. ...temperature and egglaying trends. Nature 391:30-31.

McCleery, R. H., R. A. Pettifor, P. Armbruster, K. Meyer, B. C. Sheldon, and C. M. Perrins. 2004. Components of variance underlying fitness in a natural population of the great tit Parus major. American Naturalist 164:E62-E72. 
ature and timing of egg-laying of European starlings. Condor $101 \rightarrow$ Sharp, P. J., I. C. Dunn, and R. T. Talbot. 1987. Sex-differences in 124-132.

$\rightarrow$ Naef-Daenzer, L., B. Naef-Daenzer, and R. G. Nager. 2000. Prey selection and foraging performance of breeding great tits Paru $\rightarrow$ major in relation to food availability. Journal of Avian Biology 31: 206-214.

the LH responses to chicken LHRH-I and LHRH-II in the domestic fowl. Journal of Endocrinology 115:323-331.

Sheldon, B. C., L. E. B. Kruuk, and J. Merilä. 2003. Natural selection and inheritance of breeding time and clutch size in the collared flycatcher. Evolution 57:406-420.

$\rightarrow$ Nager, R. G., and A. J. van Noordwijk. 1992. Energetic limitation ir $\rightarrow$ Silverin, B. 1995. Reproductive adaptations to breeding in the north. the egg-laying period of great tits. Proceedings of the Royal Society B: Biological Sciences 249:259-263.

Naguib, M., A. Kazek, S. V. Schaper, K. van Oers, and M. E. Visser. 2010. Singing activity reveals personality traits in great tits. Ethology 116:763-769.

$\rightarrow$ Nussey, D. H., E. Postma, P. Gienapp, and M. E. Visser. 2005. Se $\rightarrow$ lection on heritable phenotypic plasticity in a wild bird population. Science 310:304-306.

$\rightarrow$ Parmesan, C., and G. Yohe. 2003. A globally coherent fingerprint or climate change impacts across natural systems. Nature 421:37-42.

$\rightarrow$ Partridge, L., B. Barrie, K. Fowler, and V. French. 1994. Thermal evolution of pre-adult life-history traits in Drosophila melanogaster. Journal of Evolutionary Biology 7:645-663.

$\rightarrow$ Peñuelas, J., and I. Filella. 2001. Responses to a warming world Science 294:793-795.

$\rightarrow$ Perfito, N., S. L. Meddle, A. D. Tramontin, P. J. Sharp, and J. C. Wingfield. 2005. Seasonal gonadal recrudescence in song sparrows: response to temperature cues. General and Comparative Endocrinology 143:121-128.

$\rightarrow$ Perrins, C. M. 1965. Population fluctuations and clutch-size in the great tit, Parus major L. Journal of Animal Ecology 34:601-647.

$\rightarrow$. 1970. The timing of birds' breeding season. Ibis 112:242255.

$\rightarrow \longrightarrow$. 1991. Tits and their caterpillar food supply. Ibis 133:49-54.

$\rightarrow$ Perrins, C. M., and R. H. McCleery. 1989. Laying dates and clutch size in the great tit. Wilson Bulletin 101:236-253.

$\rightarrow$ Petavy, G., J. R. David, P. Gibert, and B. Moreteau. 2001. Viability and rate of development at different temperatures in Drosophila: a comparison of constant and alternating thermal regimes. Journal of Thermal Biology 26:29-39.

Pigliucci, M. 2001. Phenotypic plasticity: beyond nature and nurturesyntheses in ecology and evolution. Johns Hopkins University Press, Baltimore.

$\rightarrow$ Prendergast, B. J., R. A. Renstrom, and R. J. Nelson. 2004. Genetic analyses of a seasonal interval timer. Journal of Biological Rhythms 19:298-311.

R Development Core Team. 2009. R: a language and environment for statistical computing. R Foundation for Statistical Computing, Vienna.

$\rightarrow$ Root, T. L., J. T. Price, K. R. Hall, S. H. Schneider, C. Rosenzweig, and J. A. Pounds. 2003. Fingerprints of global warming on wild animals and plants. Nature 421:57-60.

$\rightarrow$ Saladin, V., D. Bonfils, T. Binz, and H. Richner. 2003. Isolation and characterization of 16 microsatellite loci in the great tit Parus major. Molecular Ecology Notes 3:520-522.

$\rightarrow$ Schaper, S. V., C. Rueda, P. J. Sharp, A. Dawson, and M. E. Visser. $\rightarrow$ 2011. Spring phenology does not affect timing of reproduction in the great tit (Parus major). Journal of Experimental Biology 214: 3664-3671.

American Zoologist 35:191-202.

$\rightarrow$ Silverin, B., and P. A. Viebke. 1994. Low temperatures affect the photoperiodically induced LH and testicular cycles differently in closely related species of tits (Parus spp.). Hormones and Behavior 28:199-206.

Silverin, B., R. Massa, and K. A. Stokkan. 1993. Photoperiodic adaptation to breeding at different latitudes in great tits. General and Comparative Endocrinology 90:14-22.

Silverin, B., J. Wingfield, K.-A. Stokkan, R. Massa, A. Järvinen, N.Å. Andersson, M. Lambrechts, A. Sorace, and D. Blomqvist. 2008. Ambient temperature effects on photo induced gonadal cycles and hormonal secretion patterns in great tits from three different breeding latitudes. Hormones and Behavior 54:60-68.

Slagsvold, T. 1976. Annual and geographical variation in the time of breeding of the great tit Parus major and the pied flycatcher Ficedula hypoleuca in relation to environmental phenology and spring temperature. Ornis Scandinavica 7:127-145.

Sokolov, L. V. 2000. Spring ambient temperature as an important factor controlling timing of arrival, breeding, post-fledging dispersal and breeding success of pied flycatchers Ficedula hypoleuca in eastern Baltic. Avian Ecology and Behaviour 5:79-104.

$\rightarrow$ Storey, C. R., and T. J. Nicholls. 1982. Low environmental temperature delays photoperiodic induction of avian testicular maturation and the onset of post-nuptial photorefractoriness. Ibis 124:172174.

Suomalainen, H. 1937. The effect of temperature on the sexual activity of non-migratory birds, stimulated by artificial lighting. Ornis Fennica 14:108-113.

Therneau, T. M., and P. M. Grambsch. 2000. Modelling survival data: extending the Cox model. Springer, Berlin.

Thomas, D. W., J. Blondel, P. Perret, M. M. Lambrechts, and J. R. Speakman. 2001. Energetic and fitness costs of mismatching resource supply and demand in seasonally breeding birds. Science 291:2598-2600.

$\rightarrow$ van Asch, M., P. H. van Tienderen, L. J. M. Holleman, and M. E. Visser. 2007. Predicting shifts in phenology in response to climate change, an insect herbivore example. Global Change Biology 13: 1596-1604.

van Balen, J. H. 1973. A comparative study of the breeding ecology of the great tit (Parus major) in different habitats. Ardea 61:1-93.

$\rightarrow$ van der Jeugd, H. P., and R. McCleery. 2002. Effects of spatial autocorrelation, natal philopatry and phenotypic plasticity on the heritability of laying date. Journal of Evolutionary Biology 15:380387.

van Noordwijk, A. J., R. H. McCleery, and C. M. Perrins. 1995. Selection of timing of great tit (Parus major) breeding in relation to caterpillar growth and temperature. Journal of Animal Ecology 64:451-458.

$\rightarrow$ Schmidt, K. H. 1984. Frühjahrstemperaturen und Legebeginn be- $\rightarrow$ Meisen (Parus). Journal of Ornithology 125:321-331.

$\rightarrow$ Sharp, P. J. 2005. Photoperiodic regulation of seasonal breeding in

birds. Annals of the New York Academy of Sciences 1040:189-199 $\rightarrow$ Verboven, N., and S. Verhulst. 1996. Seasonal variation in the inci-

Verbeek, M. E. M., P. J. Drent, and P. R. Wiepkema. 1994. Consistent individual differences in early exploratory behaviour of male great tits. Animal Behaviour 48:1113-1121. 
dence of double broods: the data hypothesis fits better than the quality hypothesis. Journal of Animal Ecology 65:264-273.

$\rightarrow$ Verhulst, S., and J. M. Tinbergen. 1991. Experimental evidence fo a causal relationship between timing and success of reproduction in the great tit Parus m. major. Journal of Animal Ecology 60:269282.

$\rightarrow$ Visser, M. E., and C. Both. 2005. Shifts in phenology due to globa- $\rightarrow$ climate change: the need for a yardstick. Proceedings of the Royal Society B: Biological Sciences 272:2561-2569.

$\rightarrow$ Visser, M. E., A. J. van Noordwijk, J. M. Tinbergen, and C. M. Lessells. 1998. Warmer springs lead to mistimed reproduction in great tits (Parus major). Proceedings of the Royal Society B: Biological Sciences 265:1867-1870.

$\rightarrow$ Visser, M. E., F. Adriaensen, J. H. van Balen, J. Blondel, A. A. Dhondt, S. van Dongen, C. du Feu, et al. 2003. Variable responses to largescale climate change in European Parus populations. Proceedings of the Royal Society B: Biological Sciences 270:367-372.

$\rightarrow$ Visser, M. E., L. J. M. Holleman, and P. Gienapp. 2006. Shifts in caterpillar biomass phenology due to climate change and its impact on the breeding biology of an insectivorous bird. Oecologia (Berlin) $147: 164-172$.

$\rightarrow$ Visser, M. E., L. J. M. Holleman, and S. P. Caro. 2009. Temperature has a causal effect on avian timing of reproduction. Proceedings of the Royal Society B: Biological Sciences 276:2323-2331.

$\rightarrow$ Visser, M. E., S. P. Caro, K. van Oers, S. V. Schaper, and B. Helm. 2010a. Phenology, seasonal timing and circannual rhythms: towards a unified framework. Philosophical Transactions of the Roya Society B: Biological Sciences 365:3113-3127.

Visser, M. E., L. te Marvelde, S. V. Schaper, A. Dawson, S. Webber, and A. Husby. 2010b. Seasonal timing in a warming world. In Climate change and birds. Proceedings of a British Ornithologists' Union conference. http://www.bou.org.uk/bouproc-net/ccb/ visser-etal.pdf.

$\rightarrow$ Visser, M. E., S. V. Schaper, L. J. M. Holleman, A. Dawson, P. Sharp, P. Gienapp, and S. P. Caro. 2011. Genetic variation in cue sensitivity involved in avian timing of reproduction. Functional Ecology 25: 868-877.

$\rightarrow$ Wada, M. 1993. Low-temperature and short days together induce thyroid activation and suppression of LH-release in Japanese quail. General and Comparative Endocrinology 90:355-363.

$\rightarrow$ Wikelski, M., M. Hau, and J. C. Wingfield. 2000. Seasonality of reproduction in a Neotropical rain forest bird. Ecology 81:24582472.

Wingfield, J. C. 1993. Control of testicular cycles in the song sparrow, Melospiza melodia melodia: interaction of photoperiod and an endogenous program? General and Comparative Endocrinology 92: $388-401$.

- 2008. Organization of vertebrate annual cycles: implications for control mechanisms. Philosophical Transactions of the Royal Society B: Biological Sciences 363:425-441.

Wingfield, J. C., and G. J. Kenagy. 1991. Natural regulation of reproductive cycles. Pages 181-241 in M. P. Schreibmann and R. E. Jones, eds. Vertebrate endocrinology: fundamentals and biomedical implications. Academic Press, New York.

Wingfield, J. C., T. P. Hahn, R. Levin, and P. Honey. 1992. Environmental predictability and control of gonadal cycles in birds. Journal of Experimental Zoology 261:214-231.

$\rightarrow$ Wingfield, J. C., T. P. Hahn, M. Wada, L. B. Astheimer, and S. Schoech. 1996. Interrelationship of day length and temperature on the control of gonadal development, body mass, and fat score in white-crowned sparrows, Zonotrichia leucophrys gambelii. General and Comparative Endocrinology 101:242-255.

$\rightarrow$ Wingfield, J. C., T. P. Hahn, M. Wada, and S. J. Schoech. 1997. Effects of day length and temperature on gonadal development, body mass, and fat depots in white-crowned sparrows, Zonotrichia leucophrys pugetensis. General and Comparative Endocrinology 107: 44-62.

Wingfield, J. C., T. P. Hahn, D. L. Maney, S. J. Schoech, M. Wada, and M. L. Morton. 2003. Effects of temperature on photoperiodically induced reproductive development, circulating plasma luteinizing hormone and thyroid hormones, body mass, fat deposition and molt in mountain white-crowned sparrows, Zonotrichia leucophrys oriantha. General and Comparative Endocrinology 131: 143-158.

$\rightarrow$ Wingfield, J. C., M. E. Visser, and T. D. Williams. 2008. Introduction. Integration of ecology and endocrinology in avian reproduction: a new synthesis. Philosophical Transactions of the Royal Society B: Biological Sciences 363:1581-1588.

$\rightarrow$ Yom-Tov, Y., and J. Wright. 1993. Effect of heating nest boxes on egg laying in the blue tit (Parus caeruleus). Auk 110:95-99.

Associate Editor: Greg Demas Editor: Judith L. Bronstein 


\title{
Appendix A from S. V. Schaper et al., 'Increasing Temperature, Not Mean Temperature, Is a Cue for Avian Timing of Reproduction"
}

\author{
(Am. Nat., vol. 179, no. 2, p. E55)
}

\section{Termination of Reproduction}

We calculated temperature effects on the timing of the termination of reproduction with Cox proportional hazard models. In 2008, late-born females stopped laying later than early-born females after experiencing a cold period in March, whereas they stopped earlier than early-born females when they started laying under cold conditions in April (table A1a; figs. A1, A2). In a model including realized temperatures, the best weighting factor was very high, indicating that the decision to stop laying was based on most recently experienced temperatures (table $\mathrm{A} 1 b$ ). Thus, after a cold temperature spell, late-born females were more likely to terminate reproduction early than early-born females. In 2009, neither treatment nor realized temperature influenced the termination of reproduction (table A1). In 2010, late-born females terminated reproduction earlier than early-born females after a late temperature rise in late spring, whereas the laying dates were similar if the temperature rise happened two weeks earlier in late spring (table A1a; figs. A1, A3). There was no effect of realized temperature on the termination date (table A $1 b$ ). We found a consistent resemblance between sisters in the termination of laying in all years (female family: $2008: \chi_{10}^{2}=30.25, P<.001 ; 2009: \chi_{14}^{2}=29.15, P=.010 ; 2010: \chi_{8}^{2}=16.52, P=$ .036), possibly showing genetic differences in temperature sensitivity between early- and late-laying families, as these varied in termination dates in response to temperature. 


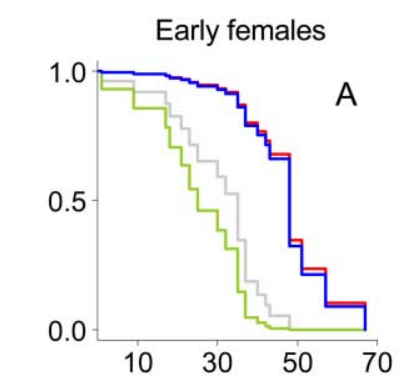

Late females
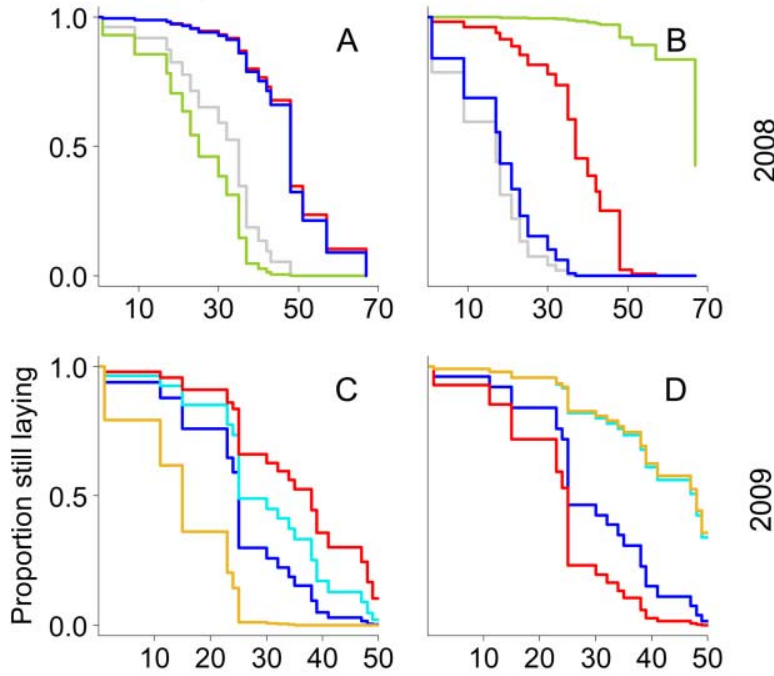

$\stackrel{\infty}{\circ}$
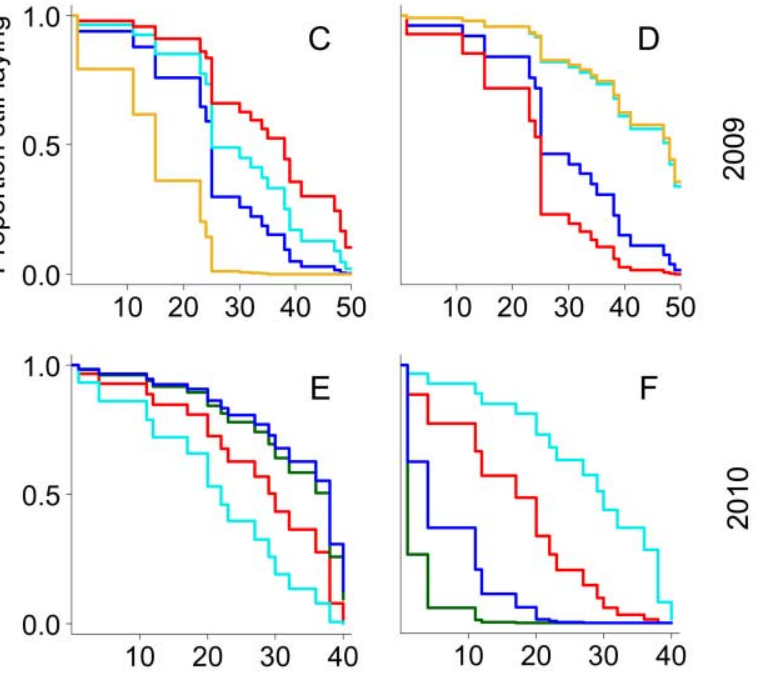

옹
웅

Figure A1: Effect of temperature treatments on the termination of laying for females from early (left) and late (right) families in climate-controlled aviaries in $2008(A, B), 2009(C, D)$, and $2010(E, F)$ : survival graphs showing the outcome of the proportional hazard model in table A1 $a$. $A, C$, and $E$ show the earliest-laying family of each year (mother's laying dates: April 7, 2008; April 3, 2009; April 8, 2010) and $B, D$, and $F$ the latest-laying family (mother's laying dates: April 20, 2008; April 26, 2009; April 18, 2010). Days represent days after the first termination date: May 5, 2008, May 1, 2009 , and April 29, 2010. A fast-descending line represents a group that stops laying early. Colors correspond to the treatments shown in figure 1. 


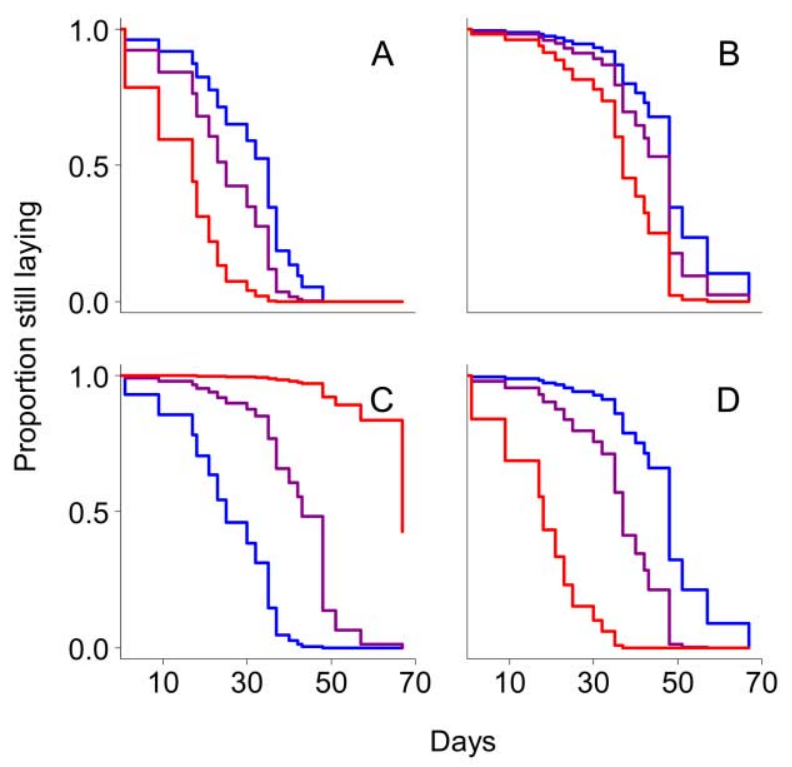

Figure A2: Termination of laying in 2008: survival graphs showing the outcome of the proportional hazard model in table A1 $a$ Each panel depicts one of the four temperature treatments: $A$, constant temperature of $15^{\circ} \mathrm{C} ; B-D$, cold period in February, March, or April, respectively. Lines show the proportions of females that were still laying from the families with the earliest (April 7 [blue]), mean (April 12 [magenta]), and latest (April 20 [red]) laying dates. Days represent days after the first termination date, May 5.

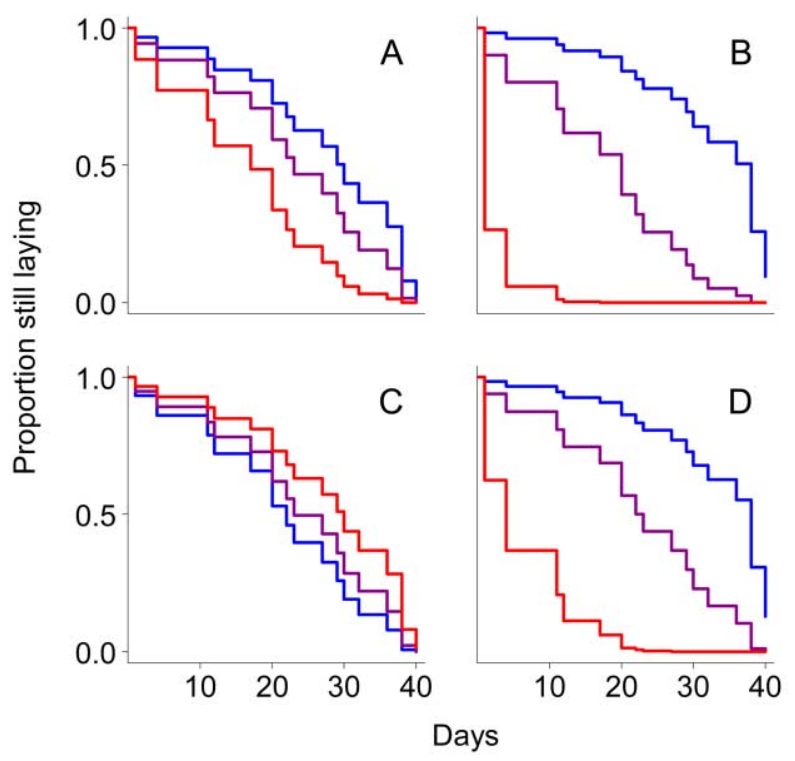

Figure A3: Termination of laying in 2010: survival graphs showing the outcome of the proportional hazard model in table A1 using temperature treatment and individual characteristics. Each panel depicts one of the four temperature treatments: $A$, fastadvancing early spring, early late spring; $B$, fast-advancing early spring, late late spring; $C$, slowly advancing early spring, early late spring; $D$, slowly advancing early spring, late late spring. Lines show the proportion of females that were still laying from the families with the earliest (April 8 [blue]), mean (April 12 [magenta]), and latest (April 18 [red]) laying dates. Days represent days after the first termination date, April 29. 
Appendix A from S. V. Schaper et al., Temperature and Timing of Reproduction

Table A1. Effects of temperature treatment, or realized temperature, and individual traits on the termination of reproduction

\begin{tabular}{|c|c|c|c|c|c|c|c|c|c|}
\hline & \multicolumn{3}{|c|}{2008} & \multicolumn{3}{|c|}{2009} & \multicolumn{3}{|c|}{2010} \\
\hline & $\chi^{2}$ & df & $P$ & $\chi^{2}$ & df & $P$ & $\chi^{2}$ & df & $P$ \\
\hline \multicolumn{10}{|l|}{ a. Temperature treatment and individual traits: } \\
\hline Temperature treatment & 9.67 & 3 & $.022 *$ & 6.58 & 3 & .087 & 12.9 & 3 & $.005^{* *}$ \\
\hline Laying date of female's mother & & & & .06 & 1 & .8 & & & \\
\hline Treatment $\times$ laying date of female's mother & 13.3 & 1 & $<.001 * *$ & 2.12 & 1 & .15 & 14 & 1 & $<.001 * *$ \\
\hline Laying date of male's mother & 1.62 & 1 & .23 & .32 & 1 & .58 & 6.36 & 1 & $.016^{*}$ \\
\hline Female personality & .09 & 1 & .77 & 2.84 & 1 & .08 & 1.08 & 1 & .31 \\
\hline Female chick weight & .63 & 1 & .43 & .14 & 1 & .71 & 8.25 & 1 & $.018 *$ \\
\hline Male personality & 2.32 & 1 & .13 & 1.79 & 1 & .14 & 11.5 & 1 & $.003^{* *}$ \\
\hline Male chick weight & .17 & 1 & .68 & .35 & 1 & .56 & .04 & 1 & .97 \\
\hline Pair composition & & & & 3.72 & 3 & .29 & & & \\
\hline \multicolumn{10}{|l|}{$b$. Realized temperature and individual traits: } \\
\hline Realized temperature & 2.58 & 1 & .11 & .01 & 1 & .92 & .05 & 1 & .84 \\
\hline Laying date of female's mother & 7.31 & 1 & $.007 * *$ & .07 & 1 & .79 & 1.44 & 1 & .24 \\
\hline Temperature $\times$ laying date of female's mother & 5.54 & 1 & $.025^{*}$ & .18 & 1 & .67 & $<.01$ & 1 & .96 \\
\hline Laying date of male's mother & .03 & 1 & .86 & .05 & 1 & .8 & .51 & 1 & .44 \\
\hline Female personality & .17 & 1 & .68 & 2.84 & 1 & .08 & 1.21 & 1 & .29 \\
\hline Female chick weight & .05 & 1 & .79 & .13 & 1 & .72 & .51 & 1 & .51 \\
\hline Male personality & 1.63 & 1 & .22 & 1.79 & 1 & .14 & .3 & 1 & .6 \\
\hline Male chick weight & 6.74 & 1 & $.028 *$ & $<.001$ & 1 & 1 & 1.17 & 1 & .27 \\
\hline Pair composition & & & & 4.63 & 1 & .2 & & & \\
\hline Best weighing factor $\alpha$ & & .2 & & & .11 & & & .01 & \\
\hline
\end{tabular}

Note: We tested how the termination of reproduction was affected by temperature treatment $(a)$ or realized temperature $(b)$ and individual traits in the years 2008-2010. The best weighting factor $\alpha$ is given in the "df" column for each year. Female family was fitted as a random effect. Statistics are given for the point of exclusion from the model. In case of significant interactions, statistics for the components are given in the presence of the interaction. Therefore, statistics for a continuous variable cannot be provided for an interaction of this variable and a factor.

$* P<.05$.

$* * P<.01$. 


\title{
Appendix B from S. V. Schaper et al., 'Increasing Temperature, Not Mean Temperature, Is a Cue for Avian Timing of Reproduction"
}

\author{
(Am. Nat., vol. 179, no. 2, p. E55)
}

\section{Onset and Duration of Molt}

Molt of the primary wing feathers was recorded biweekly in 2008 and weekly in 2009 and 2010. The molt score was calculated following Dawson and Newton (2004), with great tit-specific parameters from Dawson (2005b). For each individual, date was linearly regressed against molt score. The onset (intercept) and speed (slope) of molt were used to calculate molt duration. In most years, nonlaying birds started molting significantly earlier than laying pairs. In general, the later a bird stopped reproducing, the later it started molting. There was no effect of temperature treatments on the onset of molt. Some birds experiencing a cold spring period in 2008 molted significantly faster, even though molt took place under constant warm conditions.

Table B1. Effects of temperature treatment and individual traits on the onset and duration of molt

\begin{tabular}{|c|c|c|c|c|c|c|c|c|c|}
\hline & \multicolumn{3}{|c|}{2008} & \multicolumn{3}{|c|}{2009} & \multicolumn{3}{|c|}{2010} \\
\hline & $\chi^{2}$ & $\mathrm{df}$ & $P$ & $\chi^{2}$ & $\mathrm{df}$ & $P$ & $\chi^{2}$ & $\mathrm{df}$ & $P$ \\
\hline \multicolumn{10}{|l|}{ Females: } \\
\hline \multicolumn{10}{|l|}{ a. Onset of molt: } \\
\hline Laying-nonlaying & 17.79 & 1 & $<.001 * *$ & 6.01 & 1 & $.014^{*}$ & .09 & 1 & .77 \\
\hline Temperature treatment & 6.27 & 3 & .099 & 2.53 & 3 & 47 & .49 & 3 & .92 \\
\hline Laying date of last egg & 21.67 & 1 & $<.001 * *$ & 14 & 1 & $<.001 * *$ & 14.60 & 1 & $<.001 * *$ \\
\hline Laying date of mother & .02 & 1 & .88 & 1.93 & 1 & .17 & .18 & 1 & .67 \\
\hline \multicolumn{10}{|l|}{$b$. Duration of molt: } \\
\hline Laying-nonlaying & 8.52 & 1 & $.004 * *$ & .50 & 1 & .48 & .03 & 1 & .86 \\
\hline Temperature treatment & 16.36 & 3 & $<.001 * *$ & 4.64 & 3 & .20 & 2.90 & 3 & .40 \\
\hline Laying date of last egg & $<.01$ & 1 & 1 & .12 & 1 & .73 & $<.01$ & 1 & .98 \\
\hline Laying date of mother & 1.09 & 1 & .30 & $<.01$ & 1 & .96 & .15 & 1 & .70 \\
\hline \multicolumn{10}{|l|}{ Males: } \\
\hline \multicolumn{10}{|l|}{ a. Onset of molt: } \\
\hline Laying-nonlaying & 1.56 & 1 & .21 & 4.73 & 1 & $.030^{*}$ & .17 & 1 & .68 \\
\hline Temperature treatment & 6.91 & 3 & .075 & 6.72 & 3 & .081 & 4.63 & 3 & .20 \\
\hline Laying date of last egg & .37 & 1 & .54 & 9.05 & 1 & $.003 *$ & 6.27 & 1 & $.012 *$ \\
\hline Laying date of mother & .13 & 1 & .72 & 1.02 & 1 & .31 & $<.01$ & 1 & .97 \\
\hline \multicolumn{10}{|l|}{$b$. Duration of molt: } \\
\hline Laying-nonlaying & .41 & 1 & .52 & .02 & 1 & .90 & .57 & 1 & .45 \\
\hline Temperature treatment & 11.17 & 3 & $.011^{*}$ & 7.23 & 3 & .065 & 2.74 & 3 & .43 \\
\hline Laying date of last egg & .23 & 1 & .63 & .66 & 1 & .42 & 1.86 & 1 & .17 \\
\hline Laying date of mother & 1.81 & 1 & .18 & $<.01$ & 1 & 1 & .91 & 1 & .34 \\
\hline
\end{tabular}

Note: Onset and duration of molt in 2008-2010 were analyzed in mixed models using family as a random effect. First, laying and nonlaying birds were compared, showing that birds that skip reproduction mostly start molting earlier than those that do not. A subsequent analysis included only laying pairs and used date of termination of reproduction, temperature treatment, and date of birth (laying date of the mother) as fixed effects. Statistics are given for the point of exclusion from the model.

$* P<.05$.

$* * P<.01$ 


\title{
Appendix C from S. V. Schaper et al., 'Increasing Temperature, Not Mean Temperature, \\ Is a Cue for Avian Timing of Reproduction"
}

\author{
(Am. Nat., vol. 179, no. 2, p. E55)
}

\section{Onset of Laying in 2008}

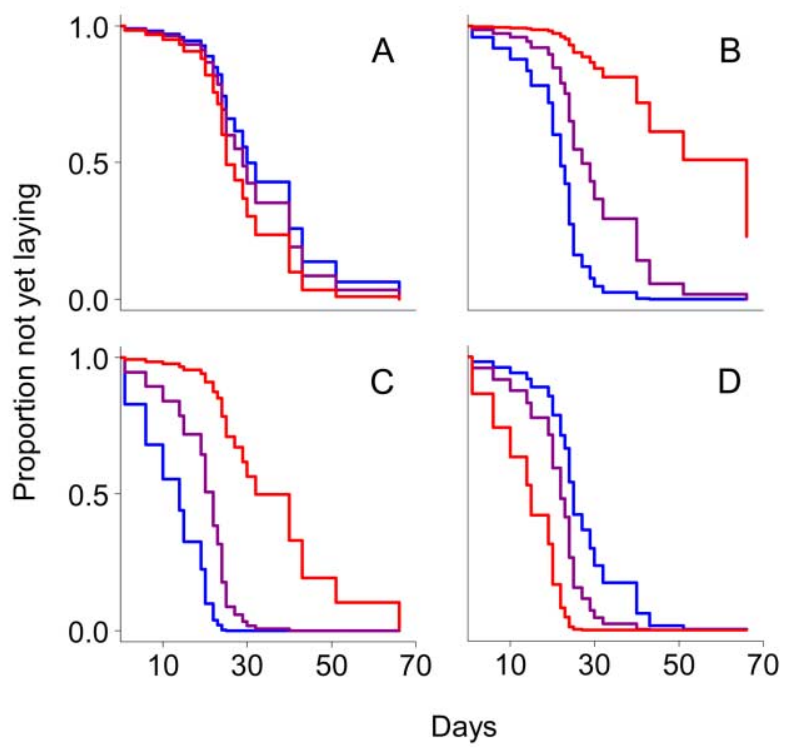

Figure C1: Survival graphs showing the outcome of the proportional hazard model in table $1 a$. Each panel depicts one of the four temperature treatments: $A$, constant temperature of $15^{\circ} \mathrm{C} ; B-D$, cold period in February, March, or April, respectively. Lines show the proportion of females that had not yet started laying at the given date for the families with the earliest (April 7 [blue]), mean (April 12 [magenta]), and latest (April 20 [red]) laying dates. Days represent days after the first laying date, April 17. In 2008, cold conditions in February or March, followed by a temperature rise, made early-laid females lay earlier compared to early-laid females in constant warm conditions and early-laid females that experienced a cold April with no subsequent temperature rise. In contrast, cold conditions in February/March made late-laid females lay significantly later. 